\title{
$1 \quad$ Nfkbid is required for immunity and antibody responses to Toxoplasma
} 2 gondii

4 Scott P. Souza ${ }^{1,3}$, Samantha D. Splitt ${ }^{1,3}$, Julia A. Alvarez ${ }^{1,3}$, Juan C. Sanchez-Arcila ${ }^{1}$, Jessica N. 5 Wilson $^{1,3}$, Safuwra Wizzard ${ }^{1}$, Zheng Luo ${ }^{4}$, Nicole Baumgarth ${ }^{4}$, Kirk D.C. Jensen ${ }^{1,2 \#}$

${ }^{1}$ School of Natural Sciences, Department of Molecular and Cell Biology, University of California, Merced

${ }^{2}$ Health Science Research Institute, University of California, Merced

${ }^{3}$ Graduate Program in Quantitative and Systems Biology, University of California, Merced

${ }^{4}$ Center for Immunology \& Infectious Diseases, and Department of Pathology, Microbiology and Immunology, University of California, Davis

17 "Email: kjensen5@ucmerced.edu

18 Keywords: B-1 cells, B-2 cells, isotype class switching, Nfkbid, IkBNS, Toxoplasma gondii, atypical strains, 


\section{SHORT TITLE}

$23 \quad$ Nfkbid-dependent immunity to T. gondii

25 ABSTRACT

26 Protective immunity to parasitic infections has been difficult to elicit by vaccines. Among parasites

27 that evade vaccine-induced immunity is Toxoplasma gondii, which causes lethal secondary

28 infections in chronically infected mice. Here we report that unlike susceptible C57BL/6J mice, A/J

29 mice were highly resistant to secondary infection. To identify correlates of immunity, we utilized

30 forward genetics to identify Nfkbid, a nuclear regulator of NF- $\kappa \mathrm{B}$ that is required for B cell

31 activation and B-1 cell development. Nfkbid-null mice (bumble) did not generate parasite-specific

32 IgM and lacked robust parasite-specific IgG, which correlated with defects in B-2 cell maturation

33 and class-switch recombination. Though high-affinity antibodies were B-2 derived, transfer of B-

341 cells partially rescued the immunity defects observed in bumble mice and were required for $100 \%$

35 vaccine efficacy in bone marrow chimeric mice. Immunity in resistant mice correlated with robust

36 isotype class-switching in both B cell lineages, which can be fine-tuned by Nfkbid gene expression.

37 We propose a model whereby humoral immunity to $T$. gondii is regulated by Nfkbid and requires

38 B-1 and B-2 cells for full protection.

40 AUTHOR SUMMARY

41 Eukaryotic parasitic diseases account for approximately one fifth of all childhood deaths, yet no

42 highly protective vaccine exists for any human parasite. More research must be done to discover

43 how to elicit protective vaccine-induced immunity to parasitic pathogens. We used an unbiased

44 genetic screen to find key genes responsible for immunity to the eukaryotic parasite Toxoplasma

45 gondii. Our screen found Nfkbid, a transcription factor regulator, which controls B cell activation

46 and innate-like B-1 cell development. Mice without $N f k b i d$ were not protected against $T$. gondii 
47 and were deficient at making antibodies against the parasite. Our survival studies of vaccinated

48 mice with and without B-1 compartments found that B-1 cells improved survival, suggesting that

49 B-1 cells act in conjunction with B-2 cells to provide vaccine-induced immunity. Nfkbid and other

50 loci identified in our unbiased screen represent potential targets for vaccines to elicit protective

51 immune responses against parasitic pathogens.

\section{INTRODUCTION}

54 The goal of vaccination is to induce immunological memory that can protect from natural infection

55 challenge. Depending on the pathogen, effective memory would need to protect also against a wide

56 variety of pathogen-specific strains encountered in nature. Such protection is termed heterologous

57 immunity and is effective against pathogen strains that differ in virulence, immune evasion, or

58 polymorphic antigens. Parasites represent a special challenge to vaccine development. Indeed, an

59 entirely protective vaccine has yet to be achieved for any human parasite [1]. The apicomplexan

60 parasite Toxoplasmas gondii, provides an excellent system to explore requirements for

61 heterologous immunity to a parasitic pathogen. T. gondii is a globally spread intracellular protozoan

62 parasite of warm-blooded animals that exhibits great genetic diversity [2]. T. gondii strains differ

63 dramatically in primary infection virulence in laboratory mice [3] and in severity of human

64 toxoplasmosis [4-6]. Such infections can be overcome by immunological memory responses

65 elicited by vaccination or natural infection. In particular, memory CD8 T cells and induction of

66 IFN $\gamma$ are primarily responsible for protection against lethal secondary infections with the widely

67 studied type I RH strain, which has a lethal dose of one parasite in naïve mice [7-9]. CD4 T cells

68 are required to help the formation of effector CD8 T cell [10] and B cell responses [11], but the

69 ability to adoptively transfer vaccine-elicited cellular immunity to naïve recipients against the type

70 I RH challenge is unique to memory CD8 T cells $[8,9]$. 
72 B cell deficient mice (muMT) are extremely susceptible to primary [12], chronic [13] and

73 secondary infections [14], despite unimpaired levels of IFN $\gamma$. Passive transfer of antibodies from

74 immunized animals into vaccinated muMT mice significantly prolongs their survival after

75 challenge [11,14]. IgM seems particularly suited for blocking cellular invasion by T. gondii [15],

76 while $\operatorname{IgG}$ can perform both neutralization [16] and opsonization functions [17]. Antibody

77 responses against $T$. gondii are dependent on CD4 T cells [11,18], and are regulated by cytokines

78 that modulate $\mathrm{T}$ follicular helper cell and germinal center B cell formation in secondary lymphoid

79 organs [19], suggesting conventional "B-2" B cell responses provide antibody-mediated immunity

80 to T. gondii.

81 In addition, "B-1" cells are innate-like lymphocytes that are known for producing self- and

82 pathogen-reactive "natural" IgM. B-1 cells are the predominant B cell compartment within the body

83 cavities, including the peritoneal and pleural spaces and contribute to antigen-specific responses to

84 many pathogens. In mouse models of secondary bacterial infections, including Borrelia hermsii,

85 Streptococcus pneumoniae and non-typhoid Salmonella, vaccination induces protective memory

86 B-1 cells to $\mathrm{T}$ cell-independent bacterial antigens (reviewed in [20]). This memory is often

87 restricted to the B-1(b), or CD5- subset of B-1 cells [21], but not in all models [22]. In the T. gondii

88 model, one study suggested that primed CD5+ B-1(a) cells can rescue B-cell-deficient mice during

89 primary infection with a low virulence strain [12]. Memory B cells are also appreciated to secrete

90 pathogen-specific $\operatorname{IgM}$ [23], and generate somatically mutated $\operatorname{IgM}$ to combat blood stage

91 secondary infection with Plasmodium [24]. Whether IgM responses to T. gondii are B-2 or B-1

92 derived is unknown. Moreover, the role of B-1 cells in promoting immunity to T. gondii during a

93 secondary infection has yet to be determined.

94 Particularly troubling for vaccine development for $T$. gondii is the lack of sterilizing 95 immunity achieved following infection [25]. Unlike the highly passaged lab type I RH strain, for 
which most immunological memory studies have been performed, the less passaged type I GT1

97 strain and atypical strains, many of which are endemic to South America, cause lethal secondary

98 infections in C57BL/6J mice and co-infect (i.e. "superinfect") the brains of challenged survivors

99 [25]. During secondary infection memory CD8 T cells become exhausted, but checkpoint blockade

100 fails to reverse disease outcome [26]. The data suggest yet unknown mechanisms are needed to

101 provide heterologous immunity to highly virulent strains of $T$. gondii. Therefore, we set out to

102 address whether additional requirements are necessary for heterologous immunity to T. gondii.

103 Through use of forward and reverse genetics, we discovered a previously unidentified essential role

104 for Nfkbid in immunity and antibody responses to $T$. gondii, and present evidence that both B-1 and

105 B-2 cells assist resistance to secondary infection with highly virulent parasite strains.

107 RESULTS

108 Non-MHC loci control resistance to secondary infection with Toxoplasma gondii

109 When mice are given a natural infection with a low virulent type III CEP strain and allowed 110 to progress to chronic infection for 35-42 days, the immunological memory that develops is known

111 to protect against secondary infections with the commonly studied lab strain, type I RH. In contrast,

112 highly virulent "atypical" strains such as those isolated from South America (VAND, GUYDOS,

113 GUYMAT, TgCATBr5) or France (MAS, GPHT, FOU) and the clonal type I GT1 strain led to 114 morbidity and mortality in C57BL/6J mice at varying frequencies, depending on the strain type and 115 their virulence factors [25]. To explore whether host genetics influenced the ability to survive 116 secondary infection, a similar experiment was performed with A/J mice. In contrast to C57BL/6 117 mice, A/J mice were resistant to secondary infection with all virulent atypical T. gondii strains 118 analyzed (Fig 1A) and cleared parasite burden as early as day 4 post challenge (Fig 1B). In contrast, 119 naïve $\mathrm{A} / \mathrm{J}$ mice succumb to infections with atypical strains (not shown). These results suggest that 120 at least one or more genetic loci controls immunity to virulent challenge. 
$\mathrm{A} / \mathrm{J}$ mice are known to be resistant to primary infections with the intermediate virulent type

122 II strain [27], and prevent cyst formation due to polymorphisms in their MHC class I H-2 molecule,

$123 \mathrm{~L}^{\mathrm{d}}[28]$. To test whether the H-2 locus contributes to immunity we compared secondary infections

124 in C57BL/10 (B10) and C57BL/10.A (B10.A) mouse strains, the latter carrying the MHC H-2 locus

125 of A/J (H-2a) in place of C57BL/6's MHC H-2 (H-2b). Compared to mice with the H-2b haplotype,

126 mice expressing H-2a had less cysts and weighed more during chronic infection with type III strains

$127(\mathrm{P}<0.04$; Fig S1). Despite their relative health at the time of challenge, B10.A mice were highly

128 susceptible (0\%-30\% survival) to secondary infection with certain atypical strains (VAND, GUY-

129 DOS, GPHT, FOU), but displayed varying degrees of resistance to others (TgCATBr5, MAS,

130 GUY-MAT; 60-100\% survival) (Fig 1A). In the case of MAS secondary infection, B10.A mice but

131 not B10 mice were highly resistant and exhibited reduced parasite burden by day 8 post challenge

132 (Fig 1B). Together, the data suggest that while the MHC H-2a locus is an important modifier of

133 resistance to certain T. gondii strains, this is not true for every challenge. Importantly, the A/J

134 genetic background encodes additional non-MHC-linked genes that control immunity to T. gondii.

135 Genetic mapping reveals four loci that correlate with immunity to Toxoplasma gondii

To identify non-MHC loci that promote resistance to secondary infection, we first analyzed

137 the outcome of infection with the type I GT1 T. gondii strain, as this strain caused lethal secondary

138 infections in B10 and B10.A, but not in A/J or first filial generation A/J x C57BL/6J mice ('F1')

139 (Fig 1C). Following secondary infections, A/J and F1 mice showed no overt symptoms of weight

140 loss, dehydration, or lethargy (not shown). However, sterile immunity was not achieved. For

141 example, the GT1 strain was present in the brains of these survivors (i.e. "superinfection"), and at

142 greater frequencies in F1 compared to A/J mice (Fig 1D). Superinfections were also detected at

143 high frequencies in B10 and B10.A surviving mice challenged with atypical strains. Overall, mice

144 of the C57BL genetic background were more prone to superinfection compared to A/J mice (Table

$145 \mathrm{~S} 1)$. It is unknown whether virulent strains of $T$. gondii have evolved to superinfect hosts with 
146 immunological memory, as previously hypothesized [25]. Nonetheless, our results underscore the

147 difficulty in achieving sterile immunity to parasites in otherwise genetically resistant hosts.

148 Then we performed secondary infection experiments with the type I GT1 strain using 26

149 recombinant inbred (RI) mice (Table S2). The AxB:BxA RI mouse panel contains an assortment

150 of homozygous $\mathrm{A} / \mathrm{J}$ and C57BL/6 alleles, which assist genetic mapping of loci that contribute to

151 various phenotypes, including those related to $T$. gondii infection [27,29]. Genetic mapping

152 revealed four distinct Quantitative Trait Loci (QTL) peaks with logarithm of the odds (LOD) scores

153 greater than 3 on chromosomes 7, 10, 11 and 17 (Fig 2A). None of the QTLs bore evidence for

154 epistatic interactions (not shown), and only the chromosome 10 QTL surpassed genome-wide

155 permutation testing $(\mathrm{n}=1000, \mathrm{P}<0.05)$. Nevertheless, an additive-QTL model including all four

156 QTLs best fit the data compared to any lesser combination of them ( $<<0.02$, ANOVA). The

157 estimated effect on the phenotypic variance observed in the RI panel is $24 \%, 41 \%, 21 \%$ and $27 \%$

158 for the chromosome (chr) 7, 10, 11 and 17 QTLs, respectively. Consistent with these estimates,

159 complete phenotypic penetrance (i.e. allelic correlation at 100\%) was not observed for any locus

160 (Fig 2B). Moreover, replacing chromosomes 7 or 10 of C57BL/6J with those of A/J conferred no

161 survival advantage to secondary infection in consomic mice (Fig S2). Regardless, small effect

162 QTLs controlling complex traits can still lead to the identification of causal genes within a QTL

163 region, as occurred for the successful identification of $M H C 1 \mathrm{~L}^{\mathrm{d}}$ as the host resistance factor to

164 chronic T. gondii infection [28].

$165 \quad$ Nfkbid is one of the most polymorphic genes within the chr7 QTL region (Mb 30.3-33.0)

166 and sits between the genetic markers that flank the highest imputed LOD score (Dataset S1). This

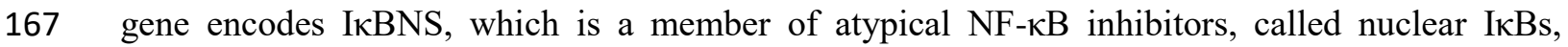

168 reflecting their restricted cellular localization. Unlike classical inhibitors of NF- $\kappa \mathrm{B}$, atypical NF-

$169 \kappa \mathrm{B}$ inhibitors can modulate NF- $\mathrm{BB}$ to induce or repress transcription [30]. Previous work has shown

170 that Nfkbid null mice completely fail to develop B-1 cells, lack circulating IgM and IgG3 
171 antibodies, and cannot respond to T-independent (T-I) type II antigens such as NP-ficoll [31-33].

172 IкBNS also promotes early plasma blast differentiation [34] and IgG1 responses to model T-

173 dependent antigens [RW.ERROR - Unable to find reference:doc:6096c5808f080d3356fb1a6a],

174 enhances T cell production of IL-2 and IFN $\gamma$ [35], supports development of T regulatory cells [36]

175 and suppresses TLR-induced cytokine expression in macrophages [37]. The tetraspanin, Tspan8,

176 is within the chr10 QTL (Mb 115.8-116.2) and is the most highly polymorphic gene between A/J

177 and C57BL/6J mice in this region (Dataset S1). Tspan8 is 6-fold more highly expressed in spleens

178 from A/J compared to C57BL/6 mice (immgen.org). Tspan8 promotes cancer metastasis [38] and

179 can impact leukocyte migration [39], but its role in immunity is largely unknown. Other

180 polymorphic gene candidates within the four QTLs are listed in Dataset S1.

181 Nfkbid on chromosome 7 is required for immunity and the generation of Toxoplasma gondii-

182 specific antibodies

183 Given the role of Nfkbid in several immune functions, degree of polymorphism and central

184 location within the chr7 QTL, the requirement for Nfkbid in immunity to T. gondii was further 185 explored. Nfkbid null "bumble" mice (C57BL/6) have previously been described, which were 186 derived from an ENU mutagenesis screen. These mice possess a premature stop codon in Nfkbid, 187 rendering them unable to support T-I antibody responses and B-1 development [32]. Bumble mice 188 survived primary infection with the low virulent CEP strain at frequencies similar to wildtype 189 C57BL/6J mice (Fig 2C) but succumbed to secondary infection three days earlier when challenged 190 with the GT1 strain (Fig 2D). Since the C57BL genetic background is uniformly susceptible to GT1 191 secondary infections used in our genetic screen, susceptibility to challenge with the commonly 192 studied type I RH strain was explored, which is normally controlled in vaccinated or chronically 193 infected mice [7-9]. Importantly, bumble mice were entirely susceptible to secondary infection with 194 the type I RH strain (Fig 2E), which exhibited greater parasite loads compared to wildtype mice 195 (Fig 2F). Moreover, bumble mice failed to generate parasite specific-IgM, and were poor producers 
196 of parasite-specific $\operatorname{IgG} 3, \operatorname{IgG} 2 \mathrm{~b}$ and $\mathrm{IgG} 2 \mathrm{a}$ antibody responses after chronic infection (Fig $3 \mathrm{~A}$ ).

197 The remaining antibodies that were secreted exhibited defects in their ability to block parasite 198 invasion of host cells (Fig 3B). Antibodies from naïve mice fail to bind T. gondii, thus natural 199 antibodies do not recognize T. gondii, consistent with previous reports [15]. Although Nfkbid 200 promotes $\mathrm{T}$ cell production of IFN $\gamma$ and IL-2 in in vitro stimulation assays [35] and promotes 201 thymic development of FOXP3+ $\mathrm{T}$ regulatory cells [36], no impairment of $\mathrm{T}$ cell cytokine 202 production was observed, nor were frequencies of FOXP3 $+\mathrm{CD} 25^{\text {hi }} \mathrm{CD} 4+\mathrm{T}$ regulatory cells altered 203 in bumble compared to wildtype mice during secondary infection (Fig S3).

204 To determine where the breakdown in the B cell response occurred in bumble mice, 205 immunophenotyping was employed. Consistent with previous reports, bumble mice have greatly 206 reduced marginal zone B cells in naïve mice and did not increase in frequency during T. gondii 207 infection (not shown). Atypical B cells (FCLR5+ CD80+ CD73+) which respond to Plasmodium 208 infections in mice [40] were also reduced in bumble compared to B6 mice following T. gondii 209 infection (not shown). The memory CD73+ B cell compartment in bumble mice bore evidence for 210 reduced class switching during $T$. gondii infection, as they remain mainly $\operatorname{IgM}+\operatorname{IgD}+$ while 211 C57BL/6J mice have higher frequencies of IgM-IgD- cells (Fig 3C). Most pronounced, however, 212 is a large accumulation of transitional stage immature B-2 cells in bumble mice that occurs during 213 chronic infection, implicating that B cell responses to $T$. gondii may require reinforcement from 214 recent bone marrow derived emigrants that is blocked in the absence of Nfkbid. Hence, Nfkbid is 215 not only an important regulator of B-1 cell development through the transitional stage of immature 216 B cell development in the steady state [41], but also for B-2 cell maturation, differentiation and 217 activation during T. gondii infection.

\section{Defective B-1 and B-2 responses underlie bumble's defect in immunity}

219 The impaired ability of bumble mice to generate parasite-specific antibodies, combined 220 with the documented collapse of the B-1 cell compartment in Nfkbid-deficient mice [31,32], 
221 prompted us to directly assess the role of B-1 mediated immunity and humoral responses to $T$.

222 gondii. First, total peritoneal exudate cells (PerC) were adoptively transferred into bumble mice at

223 day 2 of birth, which allows optimal B-1 engraftment and self-renew for the life of the animal [42].

224 Then, bumble mice that received total PerC transfers were infected with the avirulent type III strain

225 at 6-7 weeks of age and given a secondary infection 35 days later with the type I RH strain (Fig

2264 A). Bumble mice receiving PerC partially reconstituted serum IgM to $\sim 40 \%$ of wildtype levels

227 (Fig S4A), consistent with previous studies [42], and had a significantly delayed time to death

228 relative to non-transferred littermates following type I RH challenge (Fig 4A). Previous studies

229 have shown B-1 cells respond to infections and create both pathogen- $[21,43]$ and microbiota -

230 specific antibodies [44]. Antibody profiling of bumble mice that received PerC transfer showed a

231 trend of increased anti-T. gondii antibody generation following chronic infection (Fig 4B), but

232 antibody reactivity to the parasite did not reach levels observed in wildtype mice, suggesting the

233 B-1 compartment has a limited role in generating high-affinity parasite-specific antibodies. The B

234 cell compartment responsible for generating parasite-specific antibody was further confirmed with

235 Igh-allotype chimeric mice which allow tracking of IgM responses of allotype-marked B-1 and B-

2362 cells [45]. In this experimental setup, endogenous B cells of the C57BL/6 background (IgH-b

237 allotype) are depleted with allotype specific anti-IgM-b antibodies and replaced with transferred

238 PerC B-1 of the IgH-a allotype which are refractory to the depletion antibodies and will engraft for

239 the life of the animal. Following removal of the depleting antibodies, the endogenous B-2 cell

240 population reemerge and are marked with anti-IgM-b antibodies, while the transferred B-1 cell are

241 marked with anti-IgM-a antibodies (Fig 4C). Assessing antibody responses generated in IgH-

242 allotype chimeric mice during a T. gondii infection revealed the presence of B-1 derived IgM-a

243 antibodies that had low reactivity to $T$. gondii at days 14 and 30 post-infection, but the majority of

244 highly reactive parasite-specific IgM-b was derived from the B-2 compartment (Fig 4D). 
246 were complicated by their high susceptible to primary infection with the CEP strain, irrespective

247 of whether they received PerC as neonates or splenic B-2 cells prior to the primary infection (Fig

248 S4C-E), thus underscoring the importance of B cells in resistance to T. gondii infection [13].

249 Instead, mixed bone marrow chimeras were generated in which irradiated bumble or wildtype

250 recipients were transferred wildtype or bumble bone marrow to reconstitute B-2 cells and the rest

251 of the hematopoietic compartment. Since B-1a cells do not efficiently reconstitute irradiated

252 recipients from adult bone marrow [46], some recipients received wildtype PerC to restore the B-1

253 compartment in this setting [43]. These and other bone marrow chimeras (not shown) all

254 succumbed to primary CEP infections (Fig S5). To bypass the susceptibility of irradiated bone

255 marrow recipients to live T. gondii infections [47], bone marrow chimeras were vaccinated with a

256 replication deficient uracil auxotroph strain (RH $\Delta o m p d c \Delta u p$ ) improving overall survival (Fig S5).

257 Whereas vaccinated wildtype recipient mice that received Nfkbid-sufficient but not bumble bone

258 marrow were able to survive type I RH challenge (Fig 4E), complete immunity was conferred only

259 when they were transferred PerC. This study also suggests that Nfkbid is important in the non-

260 hematopoietic lineage, as complete immunity was restored only in wildtype but not bumble

261 recipients (Fig 4E). In summary, our reconstitution studies emphasize the importance of Nfkbid

262 sufficiency in multiple compartments and highlight B-1 cells as an important contributor to $T$.

263 gondii immunity.

264 Evidence for enhanced B-1 and B-2 cell activation in resistant A/J mice

265 Since Nfkbid has a profound effect on the maturation and activation of multiple B cell

266 populations in the C57BL/6J background, we extended our analysis of the humoral response to the

267 resistant $\mathrm{A} / \mathrm{J}$ background. A/J mice were found to have a superior IgG response to parasite lysate

268 antigen during secondary infections (Fig 5A), suggesting enhanced humoral responses in this

269 background. Within the spleen, both susceptible C57BL/6J and resistant A/J mice produced similar 
271 populations during infection (not shown), however in A/J mice these compartments were drastically

272 increased in their class-switch recombination frequencies during secondary infection (Fig 5B). The

273 enhanced class switch potential of resistant mice was also observed in B-1 cells. Within the

274 peritoneal B-1 cell compartment $\left(\mathrm{CD} 19+\mathrm{B} 220{ }^{\text {int }} \mathrm{CD} 11 \mathrm{~b}+\right)$ increased percentages of CD5- B-1b

275 cells were observed during secondary infection in A/J mice, which appear to have downregulated

276 their BCR as evidenced by being $\operatorname{IgM}^{\mathrm{lo}}$ (Fig 6A-B). To further validate these findings, frequencies

277 of class switched IgM-IgD- CD5+ (B-1a) or CD5- (B-1b) cells within the CD43+ B-1 cell

278 compartments of the peritoneum (not shown) and spleen were determined, and a similar trend was

279 observed (Fig 6C). Following infection, B-1 cells in the spleens of A/J mice maintained high levels

280 of BAFFR and TACI expression and expressed higher levels of surface CD138 relative to

281 C57BL/6J mice (Fig 6D-E), markers known to be induced by Nfkbid and important for B cell

282 activation and differentiation into antibody secreting cells [34]. In addition to differences in

283 humoral immunity, an increase in peritoneal CD8 T cell in vitro recall production of IFN $\gamma$ was

284 noted in A/J relative to $\mathrm{C} 57 \mathrm{BL} / 6 \mathrm{~J}$ mice, however other parameters, including granzyme B and IL-

2852 expression and CD4 T cell responses were similar (Fig S6). Collectively these data suggest that

286 while CD8 T cell production of IFN $\gamma$ is enhanced in resistant mice, and likely contributes to their

287 resistance, B-2 and B-1 cells participate in a strikingly enhanced humoral response in A/J mice,

288 offering insight into how immunity against parasitic infections may be achieved.

289 B-1 cells in resistant $\mathbf{A} / \mathbf{J}$ mice have enhanced germline transcription of Ighg constant regions,

290 class switch recombination and different activation profiles

The diminished antibody response in bumble mice as well as the B cell phenotypic 
naïve, chronic and secondary infection states (Dataset S2). GO term enrichment analysis consistently found type I and II interferon signaling and immune defense signatures as being enriched in the most differentially regulated genes among B cells following infection irrespective of genetic background (Fig S7A, not shown). Looking specifically at CD5- B-1b cells in A/J mice, which bore evidence for enhanced activation (Fig 6), pathway enrichment analysis of genes differentially upregulated on day 5 of secondary infection compared to the naïve state found additional signatures of TLR-signaling, complement activation and somatic recombination (Fig S7A). Germline transcription of Ighg1, Ighg3, Ighg2b, and Ighg2a/c was greatly enhanced in CD5B-1b cells from A/J compared to C57BL/6J mice on day 5 of secondary infection (Fig 6F), suggesting heightened isotype class switching occurred in mice on the resistant background. Consistent with their IgM-IgD- phenotype (Fig 6B 6C), both B-1a and B-1b cells underwent significant IgG isotype class-switching as revealed by intracellular staining, which was readily observed in the splenic environment of $\mathrm{A} / \mathrm{J}$ mice (Fig $6 \mathrm{G}-\mathrm{H}$ ) where activated B-1 cells migrate to secrete antibody [RW.ERROR - Unable to find reference:doc:60996ae58f08a04c290530c2].

309 Moreover, Scimp an adaptor for TLR4 signaling [50], Semaphorin7 a noted inducer of 310 inflammatory cytokines [51], the alarmins S100a8 and S100a9, and genes associated with tissue 311 tolerance including Retnlg and Slpi, were specifically upregulated in CD5- B-1b cells from A/J 312 compared to C57BL/6 mice on day 5 of challenge (Fig S7B). Gene Set Enrichment Analysis 313 (GSEA) of CD5- B-1b transcriptional variation between mice on day 5 of challenge detected 314 correlation with gene sets that distinguish B cells following vaccination with different TLR315 stimulating adjuvants (MPL vs R848, GSE25677) (Fig S7C). In summary, the transcriptomics data 316 suggest in the resistant $\mathrm{A} / \mathrm{J}$ background, but not in $\mathrm{C} 57 \mathrm{BL} / 6 \mathrm{~J}$ mice, B-1 cells undergo Ig class 317 switch recombination, perhaps through enhanced TLR-signaling.

\section{Gene dosage of $N$ fkbid impacts parasite-specific IgG1 responses}



expression levels. To investigate this possibility, we quantified Nfkbid expression within our

322 transcriptomic dataset as well as by qPCR. B cells from C57BL/6J mice had greater expression of

323 Nfkbid relative to A/J, particularly at the chronic infection stage (Fig 7A). Because Nfkbid

324 expression differences could reflect heightened responsiveness to parasite load, we stimulated

325 enriched peritoneal and splenic B cells from A/J and C57BL/6J mice with LPS and noted that B

326 cells from C57BL/6J mice had on average 1.5- to 2-fold greater induction of Nfkbid transcripts

327 relative to $\mathrm{A} / \mathrm{J}($ Fig $7 \mathrm{~B})$.

328 To explore how gene dosage of Nfkbid impacts antibody responses generated against $T$.

329 gondii, serum from chronically infected bumble heterozygotes (Nfkbid+/-), C57BL/6J, and A/J

330 mice were analyzed. Although parasite-specific IgM and IgG3 did not differ between mouse strains

331 (not shown), increased parasite-specific IgG1 serum responses were observed in $\mathrm{A} / \mathrm{J}$ relative to

332 C57BL/6 mice, a response that was phenocopied for IgG1 in bumble heterozygotes (Fig 7C-D).

333 The increase in IgG1 was also reflected in CD138+ plasma cell differentiation in the bumble

334 heterozygotes (Fig 7E-F), consistent with previous reports that Nfkbid regulates plasma blast and

335 IgG1 responses [RW.ERROR - Unable to find reference:doc:6096c5808f080d3356fb1a6a]. Hence,

336 while Nfkbid is required for the generation of $\operatorname{IgM}$ and robust $\mathrm{IgG}$ responses against $T$. gondii, gene

337 dosage of Nfkbid further controls IgG1 isotype profiles, presenting Nfkbid as tunable modulator of

338 antibody IgG responses to parasites. Of note, when $N f k b i d+/-$ mice were given secondary infections

339 with the GT1 strain, all mice succumbed to the challenge (not shown), observations that are

340 consistent with a multiple-QTL model for T. gondii immunity and apparent need for additional

341 modifiers on chromosomes 10 and 17 to survive highly virulent challenges. 

novel determinants of immunity to parasites. An unbiased genetic screen identified Nfkbid, a tunable regulator of humoral responses to parasites. Within the C57BL/6J background, Nfkbid is

347 required for maturation and class switching of B-2 cells during chronic $T$. gondii infection. While

348 B-2 responses dominate the antibody response in this background, the lack of B-1 cells appear 349 partially responsible for the immunity defect observed in bumble and are required for immunity in 350 bone marrow chimeric mice. In contrast, survival against $T$. gondii infection in resistant mice 351 correlates with a strong layered humoral response: enhanced activation and class-switching in both 352 B-1 and B-2 cells. In this context, B-1 cells may assist the B-2 response to provide full immunity 353 to challenge. The ability of B-1 cells to make parasite-specific antibodies, though of lower affinity, 354 potentially amplifies B-2 immune responses to $T$. gondii through internalization of B-1 cell-derived 355 antigen-antibody complexes [52], assisting MHCII antigen presentation for CD4 T cell help [53]. 356 Moreover, the effect of B cell-mediated immunity to $T$. gondii and other pathogens is likely 357 underestimated in murine models using the C57BL/6 background, as enhanced B-1 and B-2 358 responses were primarily observed in $\mathrm{A} / \mathrm{J}$ mice.

359 Though the exact pathway remains to be investigated, Nfkbid is downstream of TLR 360 signaling in B cells [31,32,34], which in B-1a cells causes them to downregulate CD5 and facilitate 361 differentiation into antibody secreting cells [44,54]. CD5 is a potent negative regulator of antigen 362 receptor signaling that renders B-1a cells unresponsive to B cell receptor (BCR)-triggering. This 363 inhibition is overcome by TLR-stimulation which causes CD5 to dissociate with the BCR, thereby 364 releasing repression of BCR-mediated signaling and antibody secretion [54] against foreign- and 365 self-antigen [44]. These data suggest CD5- B-1b cells may represent an activated state of B-1 cells, 366 and calls into question a strict division of labor between these two subsets. This supposition would 367 fit several of the observations made in our system, including evidence for enhanced class switch 368 recombination and TLR-gene signatures observed in the CD5- B-1 cells of the resistant 
background. In addition, BAFFR and TACI are known inducers of class-switch recombination [55], and increased expression of these receptors may further lower the threshold of activation and

371 differentiation into CD138+ plasmablasts/plasma cells, all of which are regulated by Nfkbid [34]

372 and occurring with greater magnitude in B-1 cells of genetically resistant A/J mice. Although class

373 switch recombination occurs with much greater frequency in B-2 cells of A/J mice, we found no 374 evidence for enhanced expression of BAFFR and TACI in this compartment following T. gondii 375 infection (not shown). Further investigation of pathways upstream of Nfkbid has the potential to 376 elucidate key requirements for $T$. gondii immunity. controlled by NF- $\mathrm{BB}$ such as BCR- or BAFF-mediated signaling [56], both of which are regulated 381 by Nfkbid [34]. Our observation of an accumulation of transitional B cells during T. gondii infection 382 in bumble mice suggest Nfkbid plays a role in stabilizing advancement out of these developmental 383 checkpoints. Nfkbid could act as a negative regulator of BCR signaling, enabling pathogen-reactive 384 B-2 cells to develop beyond negative selection that would otherwise occur as antigen accumulates 385 in secondary lymphoid organs over time. Alternatively, Nfkbid could be a positive regulator of NF$386 \mathrm{\kappa B}$ signaling, increasing the strength of BCR signaling to enable transitional B cells to become mature B cells. In both cases, a developmental defect likely restricts the pool of $T$. gondii-reactive mature B cells, preventing replenishment of antibody secreting cells during infection, culminating in the low parasite-specific antibody titers observed in bumble mice. 
394 surprising, the Nfkbid polymorphism in a stand-alone fashion did not fully restore immunity, as

395 inferred from chromosome 7 consomic mice and by our attempts to mimic the lower gene

396 expression observed in resistant mice through heterozygous expression. Whereas polymorphic

397 Nfkbid contributes $21 \%$ to this phenotype, perhaps by regulating plasma cell differentiation (Fig 7),

398 this smaller effect QTL was instrumental in identifying Nfkbid, where a more drastic gene

399 inactivation revealed its role in multiple compartments in bumble mice, notwithstanding its

400 requirement for humoral immunity.

401 In summary, heterologous immunity to a parasitic pathogen should, at a minimum, prevent

402 disease against a wide variety of strains that differ in virulence or polymorphic antigens. An ideal

403 parasite vaccine would entirely protect against re-infection and induce sterile immunity, thought

404 possible since re-infection studies were first performed in mice [57] and humans immunized with

405 irradiated sporozoites and Plasmodium sp. challenge [58]. Yet, only one partially protective vaccine

406 is in use for any human parasitic pathogen, RTS,S/AS01, which has low efficacy for malaria

407 prevention [59]. Our findings highlight the role of both innate and conventional B cells in humoral

408 immunity to $T$. gondii, introducing B-1 cells as a potential vaccine target along with B-2 cells to

409 maximize humoral immunity to parasitic infections. Moreover, we present a modulator of antibody

410 responses against parasitic infections, Nfkbid, a transcriptional regulator that can tune B cell

411 responses to provide an overall effective class-switched antibody response against parasites.

\section{MATERIAL AND METHODS}

\section{$414 \quad$ Parasite strains and cell lines}

415 Human foreskin fibroblasts (HFFs) monolayers were grown in DMEM (4.5 g/L D-glucose) (Life

416 Technologies) supplemented with $2 \mathrm{mM}$ L-glutamine, 20\% fetal bovine serum (FBS) (Omega

417 Scientific), $1 \%$ penicillin-streptomycin, and $0.2 \%$ gentamycin (Life Technologies). Mouse

418 Embryonic Fibroblasts (MEFs) were grown in DMEM (4.5 g/L D-glucose) (Life Technologies) 
419 supplemented with 10\% fetal bovine serum (FBS) (Omega Scientific), 20mM HEPES, 1\%

420 penicillin-streptomycin, and $0.2 \%$ gentamycin (Life Technologies). Toxoplasma gondii strains

421 were passaged in HFFs in 'Toxo medium' (4.5 g/L D-glucose, L-glutamine in DMEM

422 supplemented with $1 \%$ FBS and $1 \%$ penicillin-streptomycin). The following clonal strains were

423 used (clonal types are indicated in parentheses): RH $\Delta k u 80 \Delta h x g p r t$ (type I), RH (1-1) GFP::cLUC

424 (type I), GT1 (type I), GT1 GFP::cLuc (type I), and CEP hxgprt- (type III). The following atypical

425 strains were used: MAS, MAS GFP::cLuc (2C8) (haplogroup 'HG' HG4), GUY-MAT (HG5),

426 FOU (HG6), GPHT (HG6), TgCATBr5 (HG7), GUY-DOS (HG10), and VAND (HG10). The

427 uracil auxotroph vaccine strain, $\mathrm{RH} \Delta u p \Delta o m p d c$ [60], was passaged in HFFs in medium containing

$428 \quad 250 \mu \mathrm{M}$ uracil.

\section{Generation of GFP-expressing GT1 strains}

430 GT1 parasites were transfected with linearized plasmids for parasite expression of GFP and click 431 beetle luciferase (GFP::cLUC), parasites were grown on HFF monolayers in T-25 flasks in Toxo 432 medium for 2 weeks. Parasites were removed from the flasks by scraping; the parasites were 433 pelleted and washed with PBS and suspended in sterile FACS buffer (2\% FBS in PBS). Fluorescent 434 parasites where then sorted via fluorescence-activated cell sorting (FACS) into a 96-well plate with 435 confluent HFF monolayers. To ensure single plaque formation in at least one of the wells, the sort 436 was titrated using the following parasite numbers: 100, 50, 25, 12, 6, 3, 2, and 1 for each well per 437 row of 8.

\section{Mice and ethics statement}

439 Female C57BL/6J (H-2b), A/J (H-2a), C57BL/10SnJ (H-2b), B10.A-H2 ${ }^{a} H 2-T 18^{a} / \mathrm{SgSnJ}(\mathrm{H}-2 \mathrm{a})$, 440 B6AF1/J (A/J x C57BL/6J F1 progeny), B6.129S2-Ighm ${ }^{t m l g g n} / \mathrm{J}$ (muMT), B6.SJL-Ptprc ${ }^{a}$ $441 P e p c^{b} /$ BoyJ (CD45.1 congenic), B6.Cg-Gpil ${ }^{a}$ Thyl ${ }^{a} \operatorname{Igh}^{a} / \mathrm{J}$ (IgH-a triple congenic mice), $442 \mathrm{C} 57 \mathrm{BL} / 6 \mathrm{~J}-\mathrm{Chr} 7^{\mathrm{A} / \mathrm{J}} / \mathrm{NaJ}$ and C57BL/6J-Chr10 $1 / \mathrm{A} / \mathrm{NaJ}$ (chromosome 7 and 10 consomic mice), and $44326(\mathrm{AxB} ; \mathrm{BxA})$ recombinant inbred (RI) mice derived from $\mathrm{A} / \mathrm{J}$ and $\mathrm{C} 57 \mathrm{BL} / 6$ founders, were 
444 purchased from Jackson Laboratories. The bumble mouse line used for this research project [32],

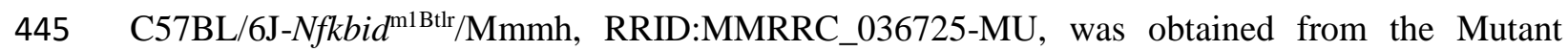

446 Mouse Resource and Research Center (MMRRC) at University of Missouri, an NIH-funded strain

447 repository, and was donated to the MMRRC by Bruce Beutler, M.D., University of Texas

448 Southwestern Medical Center. Bumble mice were crossed to C57BL/6J to generate F1 bumble

449 heterozygotes (Nfkbid+/-).

450 Mice were maintained under specific pathogen free conditions at UC Merced. Every effort

451 was made to ensure unnecessary stress on the animals was avoided. Mouse work was performed in

452 accordance with the National Institutes of Health Guide to the Care and Use of Laboratory Animals.

453 All protocols have been reviewed and approved by UC Merced's Committee on Institutional

454 Animal Care and Use Committee. UC Merced has an Animal Welfare Assurance filed with OLAW

455 (\#A4561-01), is registered with USDA (93-R-0518), and the UC Merced Animal Care Program is

456 AAALAC accredited (001318).

\section{Parasite infections}

458 Parasite injections were prepared by scraping T-25 flasks containing vacuolated HFFs and 459 sequential syringe lysis first through a $25 \mathrm{G}$ needed followed by a $27 \mathrm{G}$ needle. The parasites were 460 spun at $400 \mathrm{rpm}$ for $5 \mathrm{~min}$ to remove debris and the supernatant was transferred, followed by a spin 461 at $1700 \mathrm{rpm}$ washing with PBS. For primary infections, mice were infected intraperitoneally (i.p.) 462 with $10^{4}$ tachyzoites of type III CEP hxgprt-. For some experiments, mice were vaccinated i.p. with $46310^{6}$ tachyzoites of RH $\Delta u p \Delta o m p d c$. For secondary infections, mice were infected I.P. with $5 \times 10^{5}$ 464 type I parasites (RH or GT1). Parasite viability of the inoculum was determined by plaque assay 465 following i.p. infections. In brief, 100 or 300 tachyzoites were plated in HFF monolayers grown in 466 a 24-well plate and 4-6 days later were counted by microscopy (4x objective).

\section{Blood plasma isolation and assessment of seroconversion}


468 All mice were assessed for sero-positivity to $T$. gondii $4-5$ weeks post primary infection. $50 \mu \mathrm{L}$ of 469 blood was isolated from mice in tubes containing $5 \mu \mathrm{L}$ of $0.5 \mathrm{M}$ EDTA on ice, pelleted and the 470 supernatant containing blood plasma was heat inactivated to denature complement at $56^{\circ} \mathrm{C}$ for 20 471 minutes and then stored at $-80^{\circ} \mathrm{C}$. HFFs were grown on coverslips and infected with GFP472 expressing RH (1-1) overnight, fixed 18 hrs later with 3\% formaldehyde (Polysciences) in PBS, 473 washed, permeabilized and blocked with PBS containing 3\% bovine serum albumin Fraction V 474 (Sigma), 0.2M Triton X-100, 0.01\% sodium azide, incubated with a 1:100 dilution of collected 475 blood plasma for $2 \mathrm{hrs}$ at room temperature, washed with PBS, and detected with Alexa Fluor 594476 labeled secondary antibodies specific for mouse IgG (cat \# A11032, Life Technologies). 477 Seropositive parasites were observed by immunofluorescence microscopy (Nikon Eclipse Ti-U).

\section{Brain superinfection assays and cyst enumeration}

479 Brains from chronically infected mice (CEP hxgprt-) that survived secondary challenge were 480 dissected, rinsed in PBS, passed through a $21 \mathrm{G}$ needle several times, pelleted and suspended in $4811 \mathrm{~mL}$ of PBS. For rederivation, $100 \mu \mathrm{L}$ of the brain homogenate was used to inoculate HFF 482 monolayers in Toxo medium. One to two weeks later, infected HFFs were syringe-lysed and plated 483 on new HFF monolayers to encourage parasite growth. Once HFFs were fully vacuolated, parasites 484 were passaged in Toxo medium supplemented with mycophenolic acid (MPA) and xanthine that 485 selects for parasites encoding a functional HXGPRT (i.e. the challenging strains) and against the 486 chronically infecting type III hxgprt- which lacks a functional HXGPRT gene. Outgrowth in MPA487 xanthine was considered evidence for superinfection. methanol, incubated for 5 minutes in microtubes (MCT-175-C, Axygen), washed and stained 
492 washed and suspended in $1 \mathrm{~mL}$ of PBS, of which several $50 \mu \mathrm{L}$ aliquots were counted by

493 fluorescence microscopy, and the number of cysts per brain were deduced.

\section{Genetic linkage analysis}

495 Quantitative trait loci (QTL) analysis was performed with the package r/QTL in R (version 3.6.1).

496 LOD scores for each marker were calculated using the Haley-Knott regression model with the

497 function 'scanone', or for all possible combination of two markers (i.e. epistatic interactions) using

498 the function 'scantwo'. 1000 permutations were performed to obtain the genome wide LOD

499 threshold for a P value of $\leq 0.05$, which was considered statistically significant. Similar results were

500 obtained with a linear mixed regression model. To estimate the effect each QTL had on the overall

501 phenotype, the function 'fitqtl' was first used to fit the data to a multiple-QTL model. Statistical

502 support was found for inclusion of all four QTLs with LOD scores > 3 compared to any lesser

503 combination of three-QTLs (ANOVA P <0.02). Individual QTL effects were then calculated under

504 the assumption of the four-QTL model, which collectively accounts for $91 \%$ of the observed

505 phenotypic variance.

\section{Cell isolation, in vitro recall infections, and FACS analysis}

507 PECs were isolated by peritoneal lavage and splenocytes obtained, as described in [26]. In brief, $5084 \mathrm{~mL}$ of FACS buffer (PBS with 1\% FBS) and 3mL of air were injected into the peritoneal cavity

509 with a $27 \mathrm{G}$ needle. After agitation, the PEC wash was poured into a conical tube. PEC washes were

510 filtered through a $70 \mu \mathrm{m}$ cell strainer, pelleted, and washed with FACS buffer before staining.

511 Spleens were dissected and crushed through $70 \mu \mathrm{m}$ cell strainers, pelleted, incubated in ACK red

512 blood cell RBC lysis buffer $\left(0.15 \mathrm{M} \mathrm{NH}_{4} \mathrm{Cl}, 10 \mathrm{mM} \mathrm{KHCO}_{3}, 0.1 \mathrm{mM}\right.$ EDTA) for 5 minutes at room

513 temperature, then washed with FACS buffer. To obtain peripheral blood leukocytes (PBLs), $50 \mu \mathrm{L}$

514 of blood was isolated from mice in tubes containing $5 \mu \mathrm{L}$ of $0.5 \mathrm{M}$ EDTA on ice, pelleted and

515 incubated in ACK lysis buffer, washed and peripheral blood leukocytes (PBLs) were suspended in $516 \quad$ FACS buffer. 
518 buffer containing Fc Block anti-CD16/32 (2.4G2) (BD Biosciences), 5\% normal hamster serum, 519 and 5\% normal rat serum (Jackson ImmunoResearch) for 20 minutes prior to staining with 520 fluorophore-conjugated monoclonal antibodies (mAbs). The following mAbs (1:100 staining 521 dilutions) were used: anti-CD1d-BV650 (1B1, BD Bioscience), anti-CD11c-eFlour 450 (N418, 522 eBioscience); anti-CD11c-eFlour 450 (N418, BD Bioscience); anti-CD45.2-eFlour 450 (104, 523 eBioscience); anti-CD4-eFlour 450 (GK1.5, eBioscience), anti-CD4-PECy7 (GK1.5, eBioscience); 524 anti-CD11b-FITC (M1/70, eBioScience), anti-CD11b-BUV395 (M1/70, BD Bioscience), anti525 CD11b-BV421 (M1/70, BD Bioscience), anti-CD11b-Pacific Blue (M1/70, BioLegend); anti526 IFN $\gamma$-PE (XMG1.2, BD Bioscience); anti-CD8 $\alpha$-APC (53-6.7, eBioscience), anti-CD8 $\alpha$-BV510 527 (53-6.7, BioLegend), anti-Ly6G-APC (1A8-Ly6g, eBioscience), anti-CD19-PerCP-Cy5.5 528 (ebio1D3, eBioscience), anti-CD19-PE (6D5, BioLegend), anti-CD19-BV785 (6D5, BioLegend), 529 anti-CD3-eFlour 780 (17A2, BD Biosciences), anti-Ly6C-PECy7 (HK1.4, BioLegend), anti530 CD23-Pacific Blue (B3B4, BioLegend), anti-CD23-AF700 (B3B4, BioLegend), anti-CD21/CD35531 FITC (7E9, BioLegend), anti-CD21/CD35-PE (7E9, BioLegend), anti-CD5-APC (53-7.3, 532 BioLegend), anti-CD43-BV510 (S7, BD Bioscience), anti-CD43-BUV737 (S7, BD Bioscience), 533 anti-CD5-PerCP-Cy5.5 (53-7.3, BioLegend), anti-CD5- Cy7-APC (53-7.3, BioLegend), anti534 CD45R/B220-Cy7-APC (RA3-6B2, anti-CD45R/B220-BUV-661 (RA3-6B2, BD Bioscience), 535 anti-CD73-Cy7-PE (eBioTY/11.9, eBioscience), anti-CD80-BV711 (16-10A1, BioLegend), anti536 FCRL5-af88 (polyclonal, R\&D systems) anti-IgM-PECy7 (RMM-1, BioLegend), anti-IgM537 BV605 (RMM-1, BioLegend), anti-IgD-FITC (11-26c.2a, BioLegend), anti-IgD-PEDazzle (11538 26c.2a, BioLegend), anti-CD138/Syndecan-1-BV510 (281-2, BD Bioscience), anti539 CD138/Syndecan-1-BV650 (281-2, BioLegend), anti-mouse-CD267/TACI-AlexaFlour-647 540 (8F10, BD Biosciences), and anti-CD268/BAFF-R-PE (7H22-E16, BioLegend). Other FACS 541 reagents included the viability dye propidium iodide (Sigma) at a final concentration of $1 \mu \mathrm{g} / \mathrm{mL}$. 
For in vitro recall, splenocytes and PerC were isolated from chronic and challenged mice

543 (day 5 or 7 following secondary infection) and $6 \times 10^{5}$ cells per well (96-well plate) were plated in

544 T cell medium (RPMI 1640 with GlutaMAX, 20\% FBS, 1\% Pen/Strep, 1mM NaPyruvate, 10mM

545 HEPES, 1.75 $\mu$ BME). Cells were infected with a type I strain (RH or GT1) strain at an MOI

546 (multiplicity of infection) of 0.2 for $18 \mathrm{hr} ; 3 \mu \mathrm{g} / \mathrm{mL}$ brefeldin A (eBioscience) was added for the

547 last $5 \mathrm{hr}$ of infection. 96-well plates were placed on ice, cells were harvested by pipetting and

548 washed with FACS buffer, blocked, and stained for surface markers. Cells were fixed with BD

549 Cytofix/Cytoperm and permeabilized with BD Perm/Wash solution (cat\# 554714, BD

550 Pharmingen), stained with anti-IFN $\gamma$-PE (XMG1.2, BD Bioscience), anti-GZB (GB11, BioLegend)

551 and anti-IL-2-APC (JES6-5H4, BioLegend) on ice for $1 \mathrm{hr}$ or overnight. Cells were then washed

552 once with BD Perm/Wash solution, once in FACS buffer, and analyzed by FACS.

$553 \quad$ For FoxP3 staining, peritoneal lavage was performed on chronic and challenged (day 7

554 following secondary infection) bumble and WT mice. Cells were washed and surface stained.

555 Fixation and permeabilization was performed with the eBioscience Foxp3/Transcription Factor

556 Staining Buffer Set (cat \# 00-5523-00) before intracellular staining with anti-Foxp3-PE (MF-14,

557 BioLegend) according to the manufacturer's recommendations. Flow cytometry was performed on

558 a Beckman Coulter Cytoflex LX, LSR II (BD Biosciences), or the Bio-Rad ZE5 and analyzed with

559 FlowJo $^{\mathrm{TM}}$ software.

$560 \quad$ For intracellular staining of IgG H/L PerC and splenocytes were surface stained with anti-

561 CD43-BV510 (S7, BD Bioscience), anti-CD19-PE (6D5, BioLegend), anti-IgD-FITC (11-26c.2a,

562 Biolegend), anti-IgM-PE/Cy7 (RMM-1, BioLegend), anti-CD5-APC (53-7.3, BioLegend), anti-

563 CD45R/B220-Cy7-APC (RA3-6B2). Cells were then fixed with BD Cytofix/Cytoperm and

564 permeabilized with BD Perm/Wash solution (cat\# 554714, BD Pharmingen), stained with anti-

$565 \operatorname{IgG}(\mathrm{H}+\mathrm{L})$-a350 (Polyclonal, Invitrogen) for 30 minutes. Cells were then washed once with BD

566 Perm/Wash solution, once in FACS buffer, and analyzed by FACS. 
567 Analysis of isotype-specific antibody reactivity to Toxoplasma gondii by flow cytometry

568 For serum reactivity analysis, syringe-lysed GFP-expressing strains (RH1-1 and GT1-GFP) were

569 fixed in 3\% formaldehyde for 20 minutes, washed twice in PBS, and plated in 96 well micro-titer

570 plates at $4 \times 10^{5}$ parasites/well. The parasites were then incubated with serum from chronically

571 infected mice, at serum concentrations ranging from $10^{-2}$ to $10^{-6}$ diluted in FACS buffer, for 20

572 minutes at $37^{\circ} \mathrm{C}$. Parasites were then washed with FACS buffer and placed on ice for incubation

573 with anti-isotype detection antibodies depending on application: anti-IgG3-BV421 (R40-82, BD

574 Bioscience), anti-IgM-PE/Cy7 (RMM-1, BioLegend), anti-IgG1-FITC (RMG1-1, BioLegend),

575 anti-IgG1-APC (RMG1-1, BioLegend), anti-IgG2b-FITC (RMG2b-1, BioLegend), anti-IgG2b-PE

576 (RMG2b-1, BioLegend), anti-IgG2a-FITC (RMG2a-62, BioLegend), anti-IgG2a-PerCP/Cy5.5

577 (RMG2a-62, BioLegend), anti-IgM-a-PE (DS-1, BD Bioscience), Anti-IgM-b-PE (AF6-78, BD

578 Bioscience).

579 Parasite neutralization assay

580 Heat-inactivated serum was used to coat live parasites for 20 minutes at $37^{\circ} \mathrm{C}$ before infecting $5815 \times 10^{5}$ mouse embryonic fibroblasts/well (MEFs) in 96 well plates. Immediately following addition 582 of parasite to MEF wells, plates were spun at 1200rpm for 3 minutes to synchronize infection. 2 583 hrs after initiation of infection, cells were placed on ice and harvested by scraping with pipette tips.

584 Cells were washed twice in FACS buffer, suspended in 1:1000 PI in FACS buffer, and then 585 analyzed by flow cytometry.

586 SDS-PAGE and immunoblotting for parasite lysate antigen

587 To generate parasite lysate antigens Toxoplasma gondii was cultured in HFF and expanded to 588 approximately $2 \times 10^{8}$ parasites. Parasites were syringe-lysed, washed with sterile $1 \mathrm{X}$ PBS and the 589 parasite pellet was lysed with ( $1 \mathrm{~mL}) 0.1 \%$ TritonX-100 detergent in 1X PBS. Solubilized parasites 590 were centrifuged at 2,000 RCF for 20 minutes to remove large debris. The supernatant was 591 aliquoted and stored at $-80^{\circ} \mathrm{C}$. Parasite lysate was reduced with $\beta$-mercaptoethanol (BME) and 


\section{RNA isolation and sequencing}

608 Peritoneal B-1a (B220 ${ }^{\text {int-neg }}$ CD19 ${ }^{\text {high }}$ CD11b+ CD5+ PI-), B-1b (B220 int-neg CD19 ${ }^{\text {high }}$ CD11b+ CD5609 PI-), or B-2 B cells (B220 ${ }^{\text {high }}$ CD19+ CD11b- PI-) were sorted into 500ul RNeasy lysis buffer using 610 a FACS ARIA II cell sorter (BD Biosciences). RNA was purified using the RNeasy mini kit (cat\# 611 74134, Qiagen) according to the manufacturer's protocol. RNA purity was tested by Qubit 612 (ThermoFisher) and Agilent 2100 BioAnalyzer for total RNA with picogram sensitivity. DNA 613 libraries were generated with a Lexogen QuantSeq-UMI FWD 3' mRNA-Seq Library Prep Kit 614 (cat\# 015). Samples were sent to UC Davis for QuantSeq 3' mRNA FWD-UMI sequencing.

\section{Gene expression analysis and data availability}


616 Raw reads were trimmed and mapped by the BlueBee genomic pipeline FWD-UMI Mouse

617 (GRCm38) Lexogen Quantseq 2.6.1 (Lexogen). In brief, reads were quality controlled with

618 'FASTQC', trimmed with 'Bbduk' to remove low quality tails, poly(A)read-through and adapter

619 contaminations, read alignments to the Mus musculus genome build GRCm38 were done with

620 'STAR', and gene reads were quantified with 'HTSeq-count'. Differentially expressed gene (DEG)

621 analysis was performed utilizing limma-voom in R version 3.6.3 in RStudio with Bioconductor

622 suite of packages. Heatmaps were generated with 'gplots'. Pathway and GO term analysis was

623 performed with MouseMine (mousemine.org), and gene set enrichment analysis was performed

624 with GSEA v4.0.3. RNA-sequencing data generated in this study has been deposited in the NCBI

625 Sequence Read Archive (Bioproject accession number PRJNA637442). All other data that support

626 the findings herein are available from the corresponding author upon reasonable request.

\section{LPS-stimulation of enriched B cells and quantitative PCR}

628 PerC and splenocytes were isolated from naïve 6-8 week-old C57BL/6J and A/J mice and enriched

629 for B cells using the EasySep Mouse Pan B cell Isolation Kit (cat\#19844, StemTech). Bead 630 enrichment for splenic samples had the addition of biotinylated anti-CD43 antibodies (clone S7,

631 BD Bioscience) to remove B-1 cells. Enriched samples were plated in a 96-well plate at 400,000

632 cells per well and stimulated with $25 \mathrm{ug} / \mathrm{ml}$ of LPS (cat\# L4391-1MG, Sigma). After 2 hrs, total

633 RNA was isolated using the Rneasy Mini Kit (cat\# 74134) and cDNA was synthesized using High

634 Capacity cDNA Reverse Transcription Kit (ThermoFisher, cat\#4368814). Quantitative PCR was

635 performed on synthesized cDNA samples using ThermoFisher TaqMan Master Mix (cat\# 4444556)

636 and TaqMan probes: Actb - Assay ID:Mm02619580_g1 (cat\# 4331182), and Nfkbid - Assay ID:

637 Mm00549082 m1 (cat\# 4331182), according to the manufacturer's protocol. Normalization of

638 Nfkbid expression in each sample was calculated in comparison to Actb expression levels. Fold

639 change in Nfkbid expression of AJ relative to that of C57BL/6J cells was determined through the

640 delta delta CT method $\left(2^{-\Delta \Delta \mathrm{CT}}\right)$. 


\section{PerC adoptive transfers and IgH allotype chimeric mouse generation}

642 PerC was harvested by peritoneal lavage of 6-12 week old C57BL/6J donor mice as described 643 above and $5 \times 10^{6}$ total peritoneal exudate cells (total PerC)/60ul PBS dose were transferred i.p. into $644 \quad 2-4$ day old bumble neonates. Allotype chimeric mouse generation was performed as previously 645 described [45]. In brief, 1-day old C57BL/6J neonates were treated with $0.1 \mathrm{mg}$ of anti-IgM-b (clone 646 AF6-78) and twice weekly thereafter treated with 0.2mg of anti-IgM-b for 6 weeks. On day 2 after 647 birth the neonates were given $5 \times 10^{6}$ total PerC from B6.Cg-Gpil ${ }^{a}$ Thy $1^{a}$ Igh ${ }^{a}$ delivered i.p. The 648 mice were then allowed to rest for 6 weeks after the last antibody treatment before infection with 649 T. gondii.

\section{Bone marrow chimeric mice generation}

651 B6.SJL-Ptprc ${ }^{a} P e p c^{b} /$ BoyJ, bumble, and C57BL/6J recipient mice were given 2 doses of 500cGy 652 with an X-Rad320 (Precision X-Ray) with a $4 \mathrm{hr}$ interval. Donor BM cells were harvested from 653 bumble and WT C57BL/6J mice, filtered with a 70um filter, incubated in ACK red blood cell lysis 654 buffer, washed with PBS and transplanted by retro-orbital injection at a concentration of $10^{7}$ 655 cells/200ul PBS dose. For BM chimeras reconstituted with PerC, $5^{*} 10^{6}$ total PerC from WT 656 C57BL/6J mice were transferred I.P. Recipient mice were then allowed to rest for 8 weeks. 657 Reconstitution was assessed at 8 weeks by FACS analysis of PBL.

\section{$658 \quad$ ELISA}

659 High-affinity protein binding microplates (Corning) were coated overnight goat anti-mouse IgM 660 (1mg/ml, Southern Biotech, cat\# 1021-01) and blocked with coating buffer containing with $1 \%$ 661 BSA (w/v) and 2\% goat serum (Omega Scientific) in PBS. Wells were washed with ELISA wash 662 buffer (1X PBS, 0.05\% TweenTM-20). Mouse serum samples were diluted 1:400 in coating buffer 663 and incubated in the wells for $1 \mathrm{hr}$. Wells were washed 5 times and secondary goat anti-IgM-HRP 664 (Southern Biotech, cat\# 1021-08) at 1:5000 dilution was incubated for $1 \mathrm{hr}$ in the wells. Wells were 665 washed several times and developed with TMB substrate (Invitrogen). Development was stopped 
666 after 20 minutes with $1 \mathrm{M} \mathrm{H}_{3} \mathrm{PO}_{4}$ stop solution. Absorbance was measured at 450nm on a BioTek

667 Epoch microplate spectrophotometer.

668 Statistics

669 Statistical analysis was performed with Graphpad Prism 8 software. Statistical significance was

670 defined as $\mathrm{P}<0.05$. $\mathrm{P}$ values were calculated using paired or unpaired two-tailed t-tests, 2-way

671 ANOVA with Tukey multiple comparison correction, and multiple t-tests with the Holm-Sidak

672 correction for multiple comparisons. Survival curve significance was calculated using log-rank

673 (Mantel-Cox) testing. Significance in time to death was calculated using the Gehan-Breslow-

674 Wilcoxon test. Differential gene expression analysis statistics were calculated using the Limma-

675 Voom R package, $\mathrm{P}$ values were adjusted with the Benjamini-Hochberg correction for multiple

676 comparisons. GO term and pathway enrichment analysis statistics were performed at

677 mousemine.org using the Holm-Bonferroni test correction. Statistical methods used for each figure

678 are indicated in the figure legends.

679

\section{ACKNOWLEDGMENTS}

681 This work was supported by NIH grants R01 AI137126, R15 AI131027, a Hellmann Fellowship

682 and an MCB departmental award to KJ; and by NIH grants U19-AI109962 and R01 AI117890 to

683 NB. The sequencing was carried out at the DNA Technologies and Expression Analysis Cores at

684 the UC Davis Genome Center, supported by NIH Shared Instrumentation Grant 1S10OD010786-

685 01. We would like to thank David Gravano and the UC Merced Stem Cell Instrumentation Foundry

686 for their assistance designing panels and utilizing instruments, supported by the DoD Research and

687 Education Program for HBCU/MSI Instrumentation Grant W911NF1910529. The authors declare

688 no conflict of interest. 
bioRxiv preprint doi: https://doi.org/10.1101/2020.06.26.174151; this version posted May 28, 2021. The copyright holder for this preprint (which

was not certified by peer review) is the author/funder, who has granted bioRxiv a license to display the preprint in perpetuity. It is made available under aCC-BY-NC-ND 4.0 International license.

690 Author Contributions: S.P.S., S.D.S., N.B. and K.J. designed research; S.P.S., S.D.S., J.A.,

691 J.C.S.A., J.W., S.W., and K.J. performed research; Z.L. and N.B. contributed new

692 reagents/analytic tools; S.P.S., S.D.S., and K.J. analyzed data; and S.P.S., S.D.S., N.B. and K.J.

693 wrote the paper.

694 Competing Interest Statement: The authors disclose no competing interests.

695

696 
A

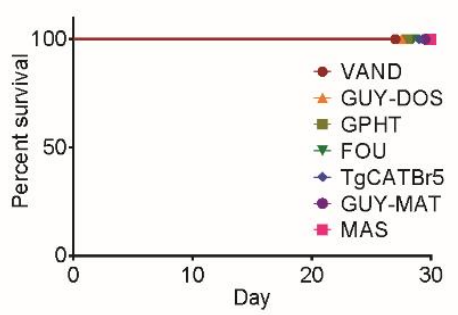

B

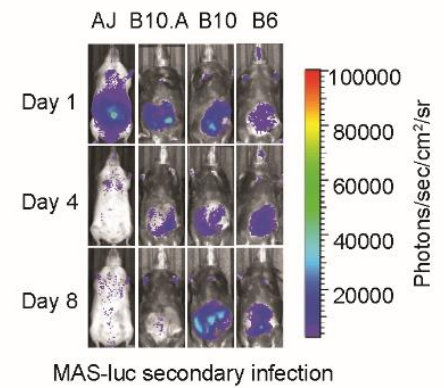

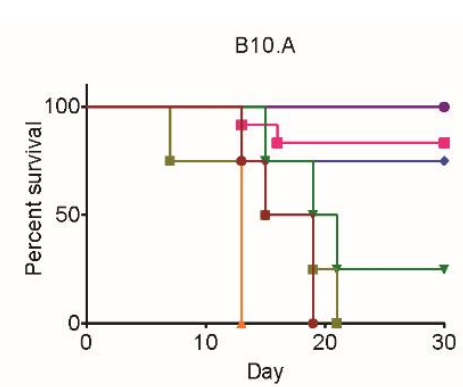

C

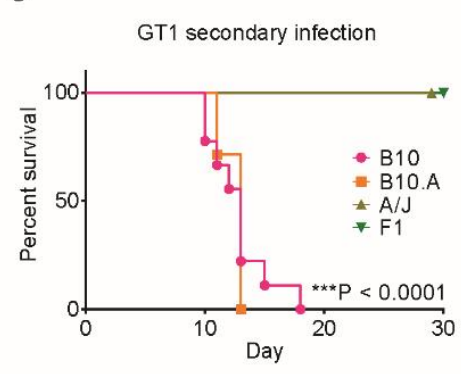

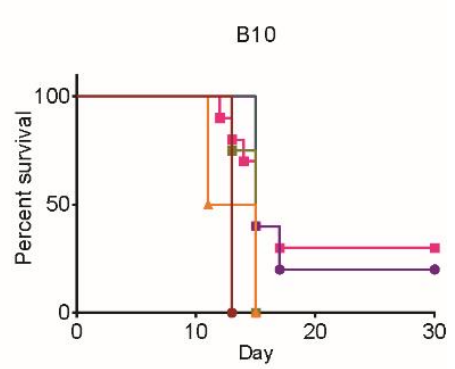

D

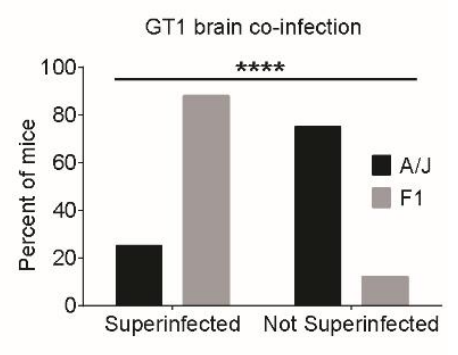

Figure 1. MHC and non-MHC alleles promote immunity to virulent Toxoplasma gondii strains in $\mathbf{A} / \mathbf{J}$ mice.

702 All mice were infected with $10^{4}$ type III CEP hxgprt-avirulent $T$. gondii parasites and allowed to 703 progress to chronic infection; then, 35 days later, mice were challenged with $5 \times 10^{4}$ of the indicated 704 strains of $T$. gondii. A) Survival of A/J, C57BL/10J (B10), and C57BL/10J.A (B10.A) mice 705 following secondary infection with atypical strains of $T$. gondii. Cumulative results are plotted from 706 1-2 experiments; $n=4$ to 12 mice per parasite strain and mouse genetic background. B) 707 Bioluminescence imaging of individual mice challenged with luciferase expressing MAS strain on days 1, 4 and 8 of secondary infection; parasite burden is shown as a heat map depicting the relative number of photons (photons/sec/cm2/sr) detected over a 5 minute exposure. C) Survival of B10 $(\mathrm{n}=5)$, B10.A ( $\mathrm{n}=5), \mathrm{A} / \mathrm{J}(\mathrm{n}=12)$, and F1 (A/J x C57BL/6, $\mathrm{n}=9)$ mice following secondary infection

711 with the type I GT1 strain; ***P<0.0001, Log-rank (Mantel-Cox) compared to A/J mice. 712 Cumulative data from 1 to 2 experiments are plotted. D) Superinfection in surviving A/J (n=12) 713 and F1 (n=9) mice following 35 days of secondary infection with the type I GT1 strain. To evaluate 
bioRxiv preprint doi: https://doi.org/10.1101/2020.06.26.174151; this version posted May 28, 2021. The copyright holder for this preprint (which

was not certified by peer review) is the author/funder, who has granted bioRxiv a license to display the preprint in perpetuity. It is made available under aCC-BY-NC-ND 4.0 International license.

714 superinfection, brain homogenate was grown in MPA-xanthine selection medium, which selects

715 for GT1 parasites expressing the endogenous HXGPRT locus and against the hxgprt- type III CEP

716 strain used to induce chronic infection. Plotted is the fraction of mice for which the presence or

717 absence of the GT1 strain was detected; **** $\mathrm{P}<0.0001$, Fisher's exact test. 

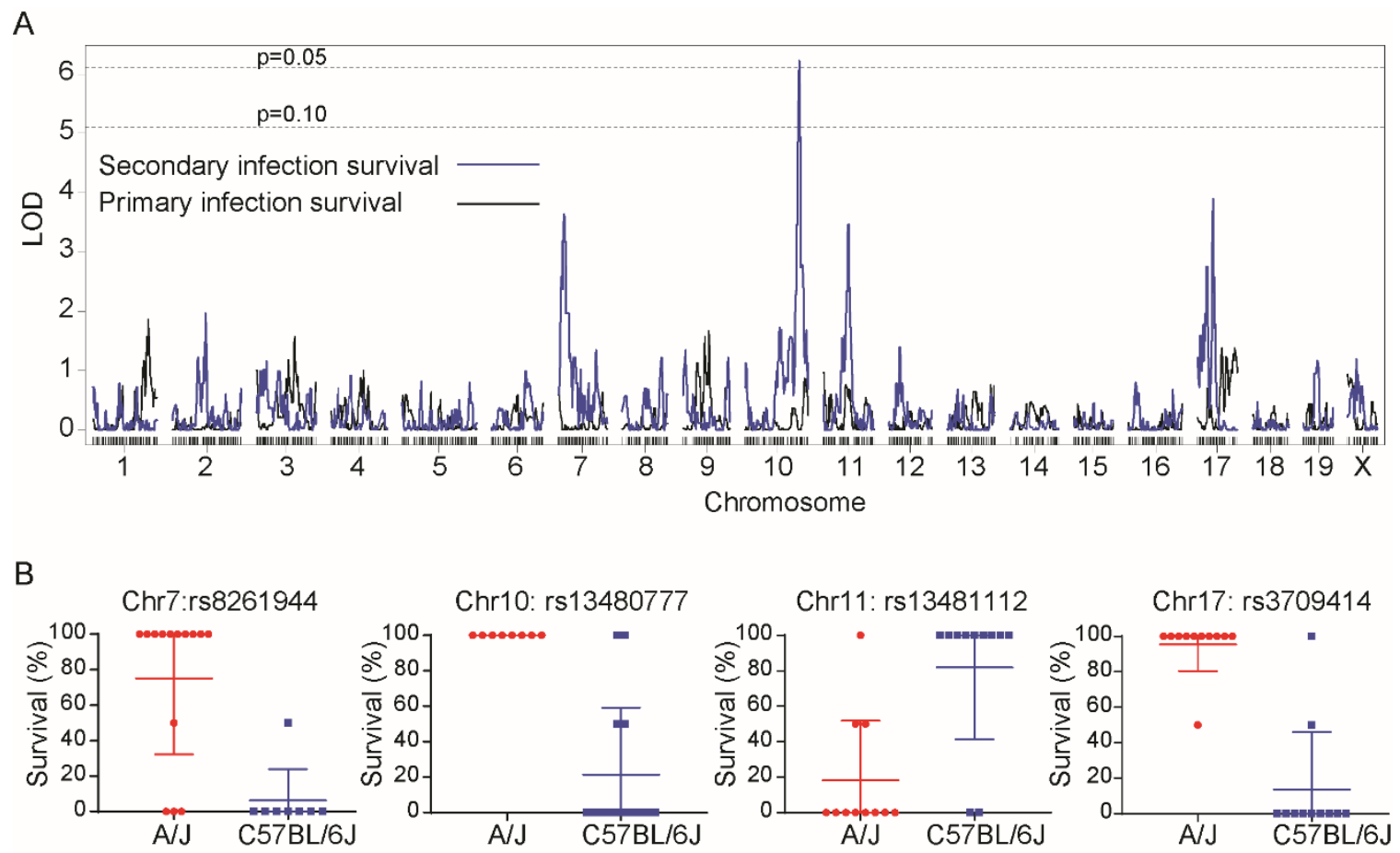

C

Type III CEP primary infection

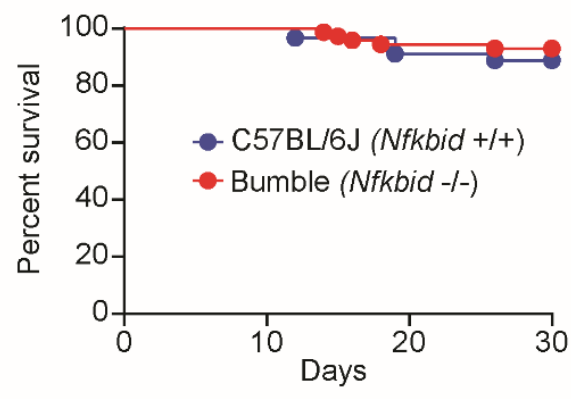

$\mathrm{E}$

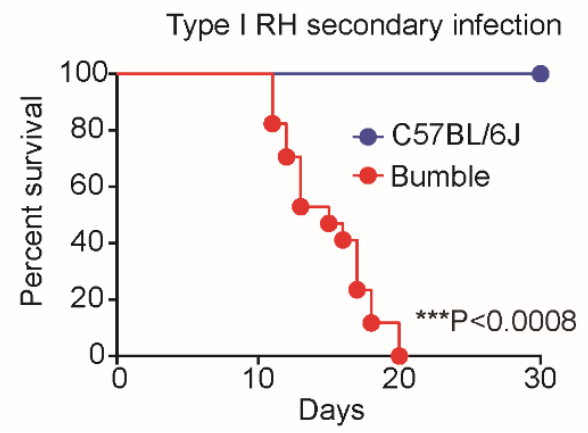

D

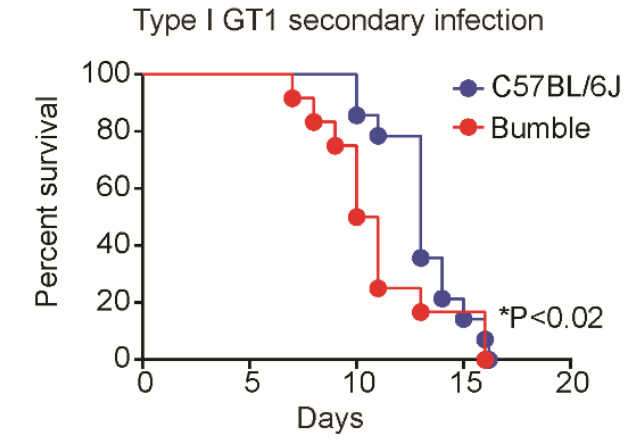

$\mathrm{F}$

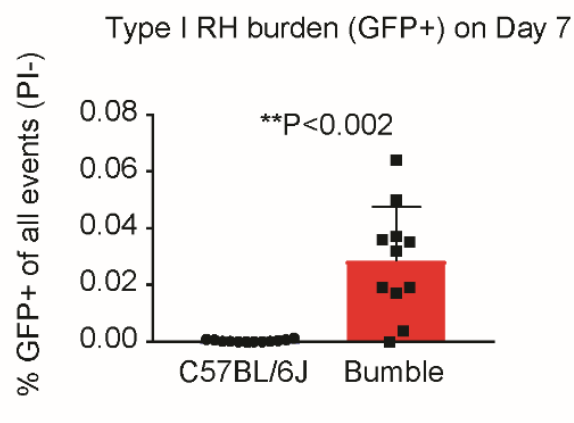




\section{Figure 2. Genetic mapping reveals Nfkbid is required for immunity to Toxoplasma gondii}

\section{3 secondary infections.}

72426 recombinant inbred (RI) mouse strains from the AxB;BxA panel were primed with $10^{4}$ type III

725 T. gondii CEP hxgprt- parasites; then, 35 days later, mice were challenged with $5 \times 10^{4}$ virulent type

726 I GT1 T. gondii parasites (n=2 per RI line). A) LOD scores for each marker were calculated using

727 Haley-Knott regression and the running LOD scores of primary (black) and secondary infection

728 survival (blue) for each genetic marker is plotted. 1000 permutations were performed to obtain the

729 genome wide threshold LOD values; $\mathrm{P}=0.10$ and 0.05 thresholds are shown. B) Effect plots for the 730 genetic markers closest to the maximal LOD scores calculated for the chromosome 7, 10,11 and

73117 QTLs are shown. Each dot indicates the percent survival of a unique RI line and whether it 732 encodes an A/J (red) or C57BL/6 (blue) allele at the specified genetic marker. C) Cumulative 733 survival of bumble (Nfkbid-/- C57BL/6) (n=71) and wildtype (C57BL/6J) (n=89) naïve mice 734 infected with the avirulent type III CEP strain. D) Survival of chronically infected bumble ( $\mathrm{n}=12)$ 735 and wildtype $(n=8)$ mice given a secondary infection with the type I GT1 strain. Cumulative 736 survival from 3 separate experiments are shown; * $\mathrm{P}<0.02$, Gehan-Breslow-Wilcoxon test. E) As

737 in B, but survival to secondary infection with the type I RH strain is shown. Cumulative survival 738 from 3 separate experiments is plotted (bumble $\mathrm{n}=17$, C57BL/6J $\mathrm{n}=4$ ); *** $\mathrm{P}<0.008$, Mantel-Cox 739 test. F) Frequency of GFP+ events in the peritoneal lavage 7 days post-secondary infection with 740 GFP-expressing type $1 \mathrm{RH}$ strain (RH 1-1). Each dot represents the result of one mouse, and 741 cumulative results are shown from 3 separate experiments (bumble $n=13$, C57BL/6J $n=17$ ); ** $\mathrm{P}<0.002$, unpaired two-tailed t-test. 
bioRxiv preprint doi: https://doi.org/10.1101/2020.06.26.174151; this version posted May 28, 2021. The copyright holder for this preprint (which was not certified by peer review) is the author/funder, who has granted bioRxiv a license to display the preprint in perpetuity. It is made available under aCC-BY-NC-ND 4.0 International license.
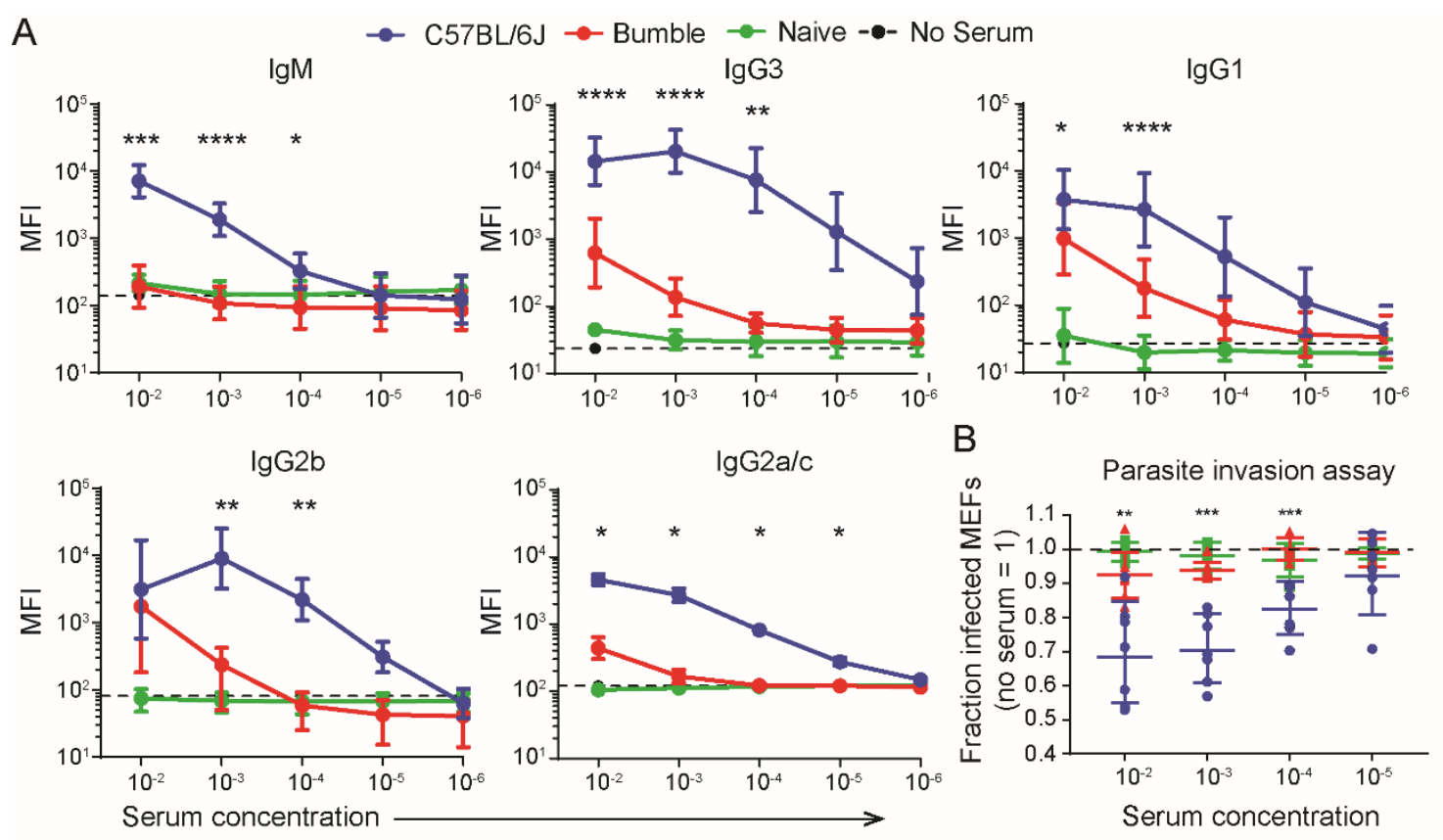

C
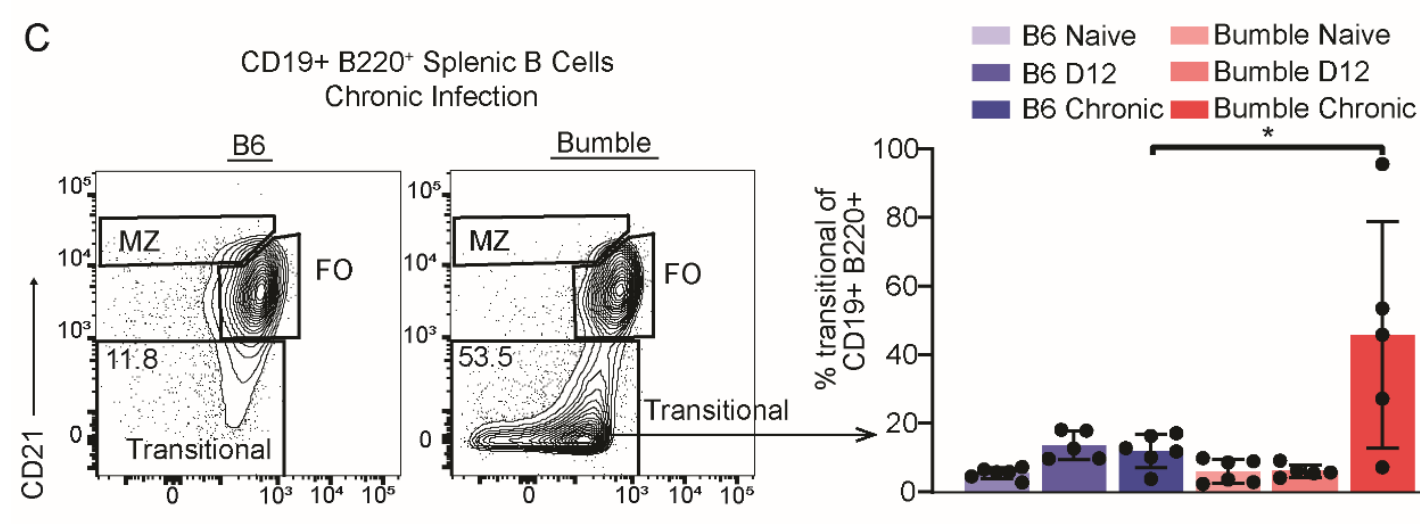

$\mathrm{CD} 23 \longrightarrow$
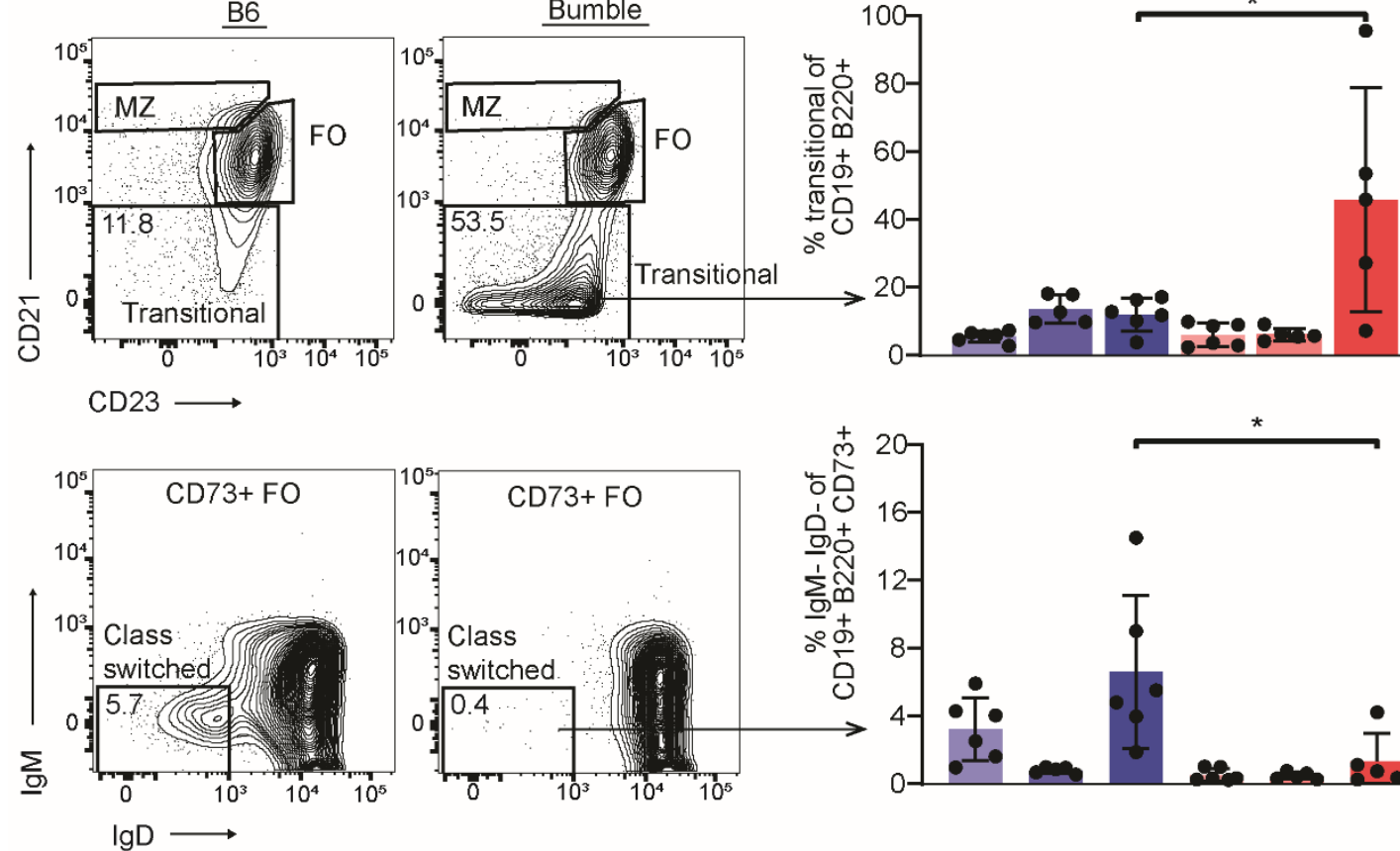

744 


\section{Figure 3. Nfkbid is required for humoral responses to Toxoplasma gondii.}

746 A) Whole fixed GFP+ parasites were incubated with serum from chronically infected mice, stained

747 with fluorescently labeled anti-isotype antibodies and assessed by flow cytometry. Quantification

748 of $T$. gondii-specific antibody isotype binding (IgM, IgG1, IgG2a/c, IgG2b, and IgG3) over a range

749 of serum concentrations is shown. Background staining in the absence of serum is indicated by the

750 dotted line for each isotype. Plotted is the cumulative average +/-SD of the geometric mean

751 fluorescence straining intensity (MFI) from 3 separate experiments (bumble $n=8$, C57BL/6J n=11).

752 B) Neutralization of GFP+ parasites coated with serum over a range of concentrations from the

753 indicated chronically infected mice. Parasites were incubated in serum for 20 minutes before

754 infection of mouse embryonic fibroblasts and assessed by FACS $2 \mathrm{~h}$ later. The fraction of infected

755 host cells (GFP+ cells) is normalized to that of parasite infections without serum. Each dot

756 represents the serum from an individual mouse and cumulative results from 3 separate experiments

757 are shown (bumble $n=8, C 57 B L / 6 J \mathrm{n}=7$, naïve $\mathrm{n}=6$ ). For $\mathrm{A}$ and $\mathrm{B}$, significance was assessed by

758 unpaired t-tests with Holm-Sidak correction for multiple comparisons; *** $\mathrm{P}<0.001, * * \mathrm{P}<0.01, *$

$759 \mathrm{P}<0.01$. C) Representative FACS plots of chronically infected bumble and B6 mice and scatter plot

760 of the frequency of splenic B-2 cell compartments quantifying transitional B cells at naïve, d12 of

761 primary infection, and chronic infection. Representative FACS plots of chronically infected bumble

762 and B6 mice and scatter plot of the frequency of IgM- IgD- cells of the CD73+ conventional

763 memory B population. Cumulative data from two experiments $\mathrm{n}=5-6$ mice/condition. * $\mathrm{P}<0.05$ by

764 unpaired two-tailed t-test. 
A
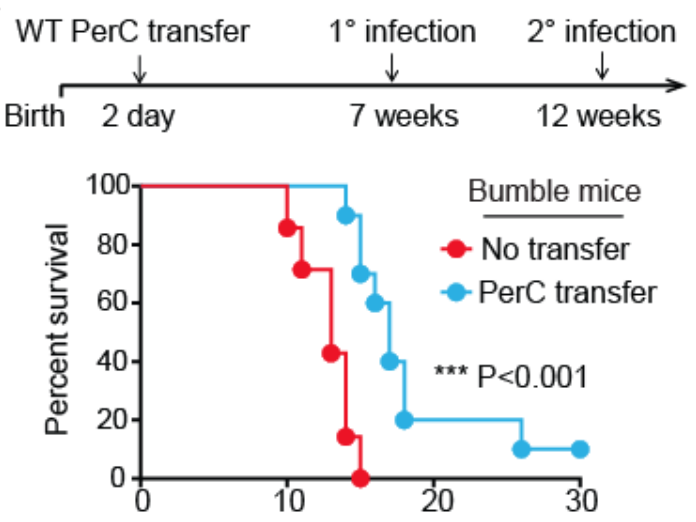

Days $2^{\circ}$ infection type I RH
B

Parasite-specific antibody (after $1^{\circ}$ infection)

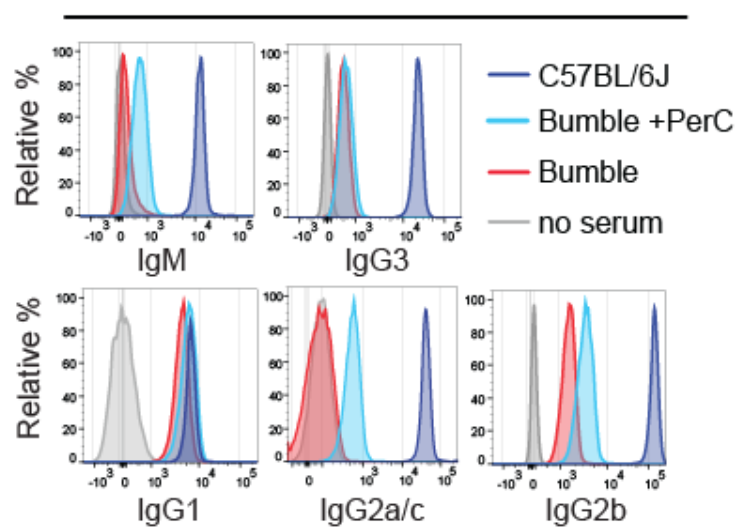

C

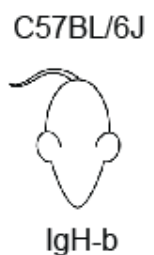

PerC IgH-a Deplete endogenous B cells
transfer

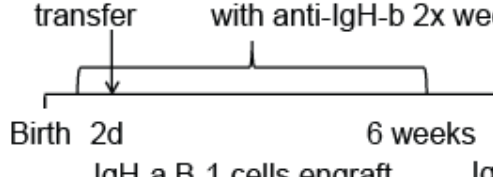

IgH-a B-1 cells engraft
IgH-b B-2 cells grow back
Primary infection $\mathrm{lg} \mathrm{H}$ chimeric mice

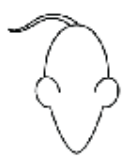

B-1: $\operatorname{lgH}-\mathrm{a}$

B-2: $\lg \mathrm{H}-\mathrm{b}$
D

Serum coated parasites (after $1^{\circ}$ infection)

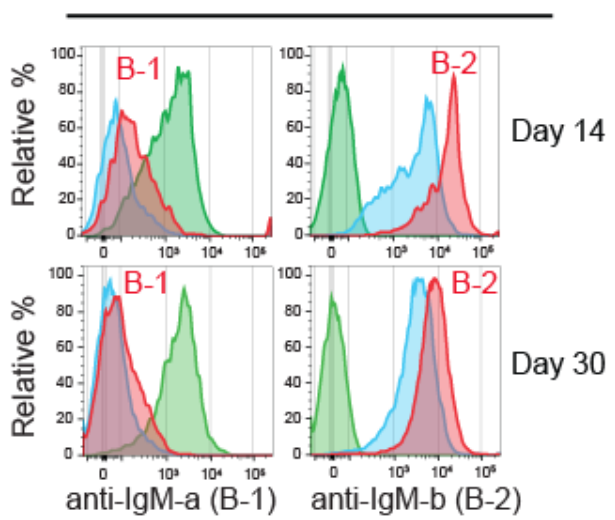

E

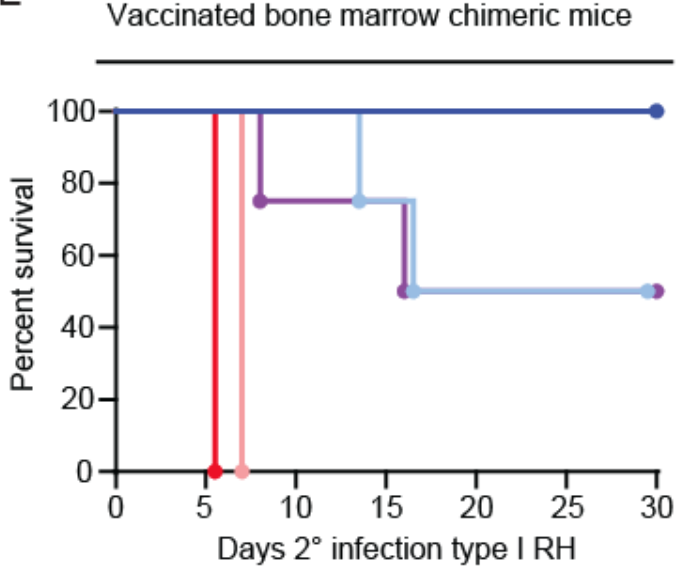

B-1 vs B-2 Irradiated recipient

BM transfer

PerC transfer

Infected IgH-a / IgH-b chimeric mice

Staining controls

Infected IgH-b mice

Infected IgH-a mice

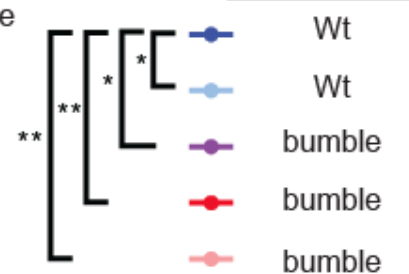

$\begin{array}{ccc}\mathrm{Wt} & \mathrm{Wt} \\ \mathrm{Wt} & - \\ \mathrm{Wt} & & \mathrm{Wt} \\ \text { bumble } & \mathrm{Wt} \\ \text { bumble } & -\end{array}$



mice.

A) Schematic of the secondary infection experiment using PerC reconstituted bumble mice. 2-4

770 day old bumble neonates were transferred $5 \times 10^{6}$ total PerC and allowed to rest for 7 weeks before

771 primary infection with the type III CEP strain. 5 weeks post-primary infection, mice were given a

772 secondary infection with the type I strain RH. Survival of bumble mice given total PerC transfers

$773(n=10)$ relative to littermate controls $(n=12)$. Cumulative survival is shown from 3 separate

774 experiments; $* * * \mathrm{P}<0.001$, Mantel-Cox test. B) Representative histograms of anti-isotype staining

775 of parasites coated in serum $\left(10^{3}\right.$ dilution for $\operatorname{IgG}, 10^{2}$ for $\left.\operatorname{IgM}\right)$ from chronically infected bumble,

776 bumble given PerC transfer, and WT mice. C) Schematic of neonatal allotype chimera generation.

777 C57BL/6J neonates were given anti-IgHb to deplete endogenous B cells at day 1 post birth and

778 twice weekly after for 6 weeks, thereby depleting the endogenous B-1 pool for the life of the animal

779 due to their restricted fetal/neonatal window of development. Neonates were given $5 \times 10^{6}$ total PerC

780 from 6-8 week old IgH-a congenic C57BL/6 mice donors. These mice then rested for 6 weeks after

781 the last depletion treatment to allow reemergence of the endogenous B-2 IgH-b cells. D)

782 Representative histograms of serum derived anti-IgM-a (B-1 derived) or anti-IgM-b (B-2 derived)

783 staining profiles of type I RH GFP+ parasites taken from the IgH allotype chimeras on day 14 and

78430 following primary type III CEP infection. Staining controls with serum from chronically

785 infected C57BL/6J IgH-b littermates, or IgH-a mice are shown. E) Irradiated bumble and WT

786 recipients (45.1 or 45.2) were given WT or bumble bone marrow (BM) with or without total WT

787 PerC (45.2). Mice were vaccinated with a replication deficient type I strain (RH $\Delta u p \Delta o m p d c)$ and

788 30d later challenged with type I RH. Cumulative survival is shown from 2-3 experiments ( $\mathrm{n}=4-9$

789 per condition); $* \mathrm{P}<0.05$ by Mantel-Cox test. 


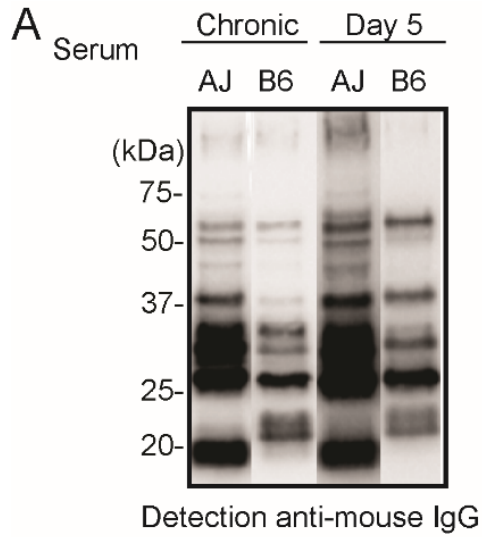

B

791

792

793

794

795

796

797

798

799

Gating strategy

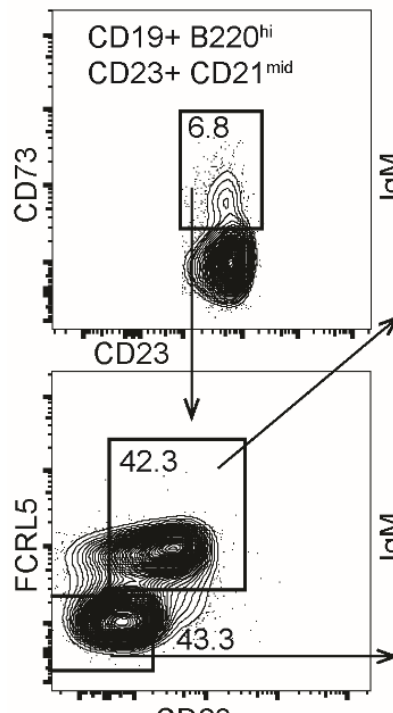

CD80

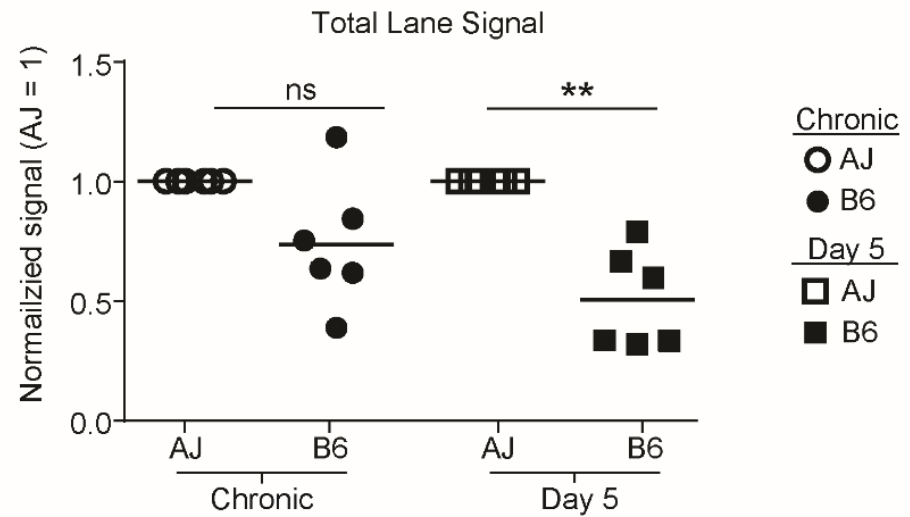

Secondary infection - Day 5

\section{5+CD80+}
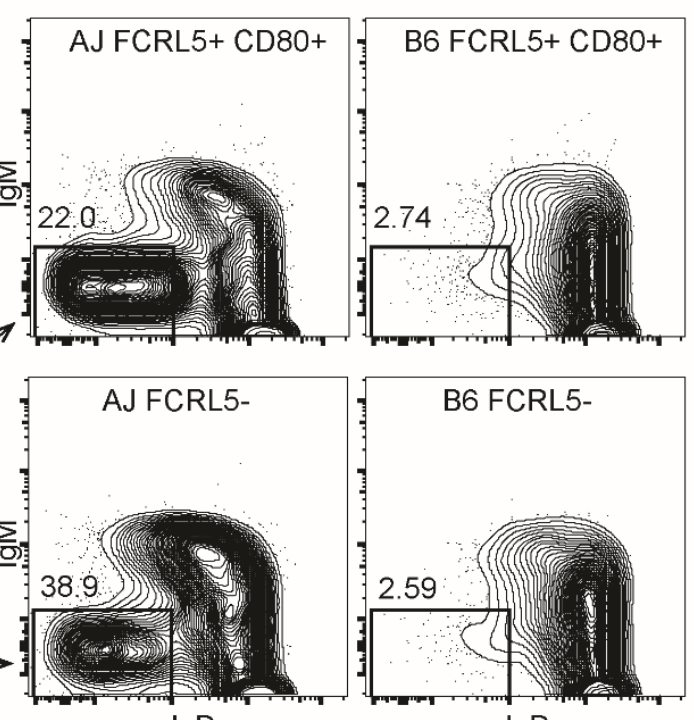

$\lg \mathrm{D}$
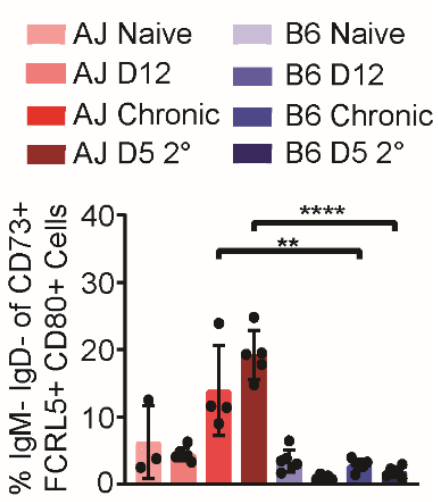

Figure 5. Immunity in A/J mice correlates with enhanced class-switching in memory B-2 cells

\section{and increased serum reactivity to parasite lysate antigen.}

A) Serum obtained from A/J and C57BL/6J mice chronically infected (CEP) or at D5 of secondary infection (GT1) were used to probe GT1 parasite lysate separated by SDS-PAGE, western blots were detected with anti-mouse IgG. "Total Lane Signal" is the signal obtained from the entire lane of $\mathrm{C} 57 \mathrm{BL} / 6 \mathrm{~J}$ compared to that of $\mathrm{A} / \mathrm{J}(=1)$; western blots were developed in tandem and analyzed by Image J. Results are from 6 individual experiments; ** $\mathrm{P}<0.01, * \mathrm{P}<0.05$; unpaired two-tailed t-tests. B) Gating strategies for identifying memory B cells. Memory B cells are identified as 
bioRxiv preprint doi: https://doi.org/10.1101/2020.06.26.174151; this version posted May 28, 2021. The copyright holder for this preprint (which

was not certified by peer review) is the author/funder, who has granted bioRxiv a license to display the preprint in perpetuity. It is made available under aCC-BY-NC-ND 4.0 International license.

800 CD19+ B220+ CD23+ CD21 ${ }^{\text {mid }}$ CD73+. Conventional memory B cells are FCRL5- CD80- while 801 atypical memory B cells are identified as FCRL5+, CD80+. Representative FACS plots of memory 802 compartments in A/J and C57BL/6J mice on day 5 of secondary infection with the type I GT1 strain 803 are shown. The frequency of class-switched (IgM- IgD-) memory cells at the indicated infection 804 states were analyzed. Each dot represents the results from an individual mouse and the cumulative 805 averages + SD from 2 experiments are plotted. N=3-6 mice per infection state. Significance was 806 assessed with an unpaired two-tailed t-test; *** $\mathrm{P}<0.0001, * * \mathrm{P}<0.01$.

807 
A

A

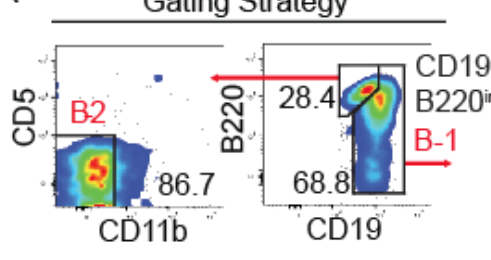

Legend

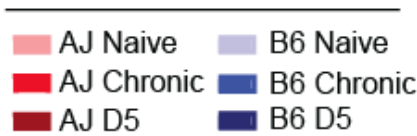

D
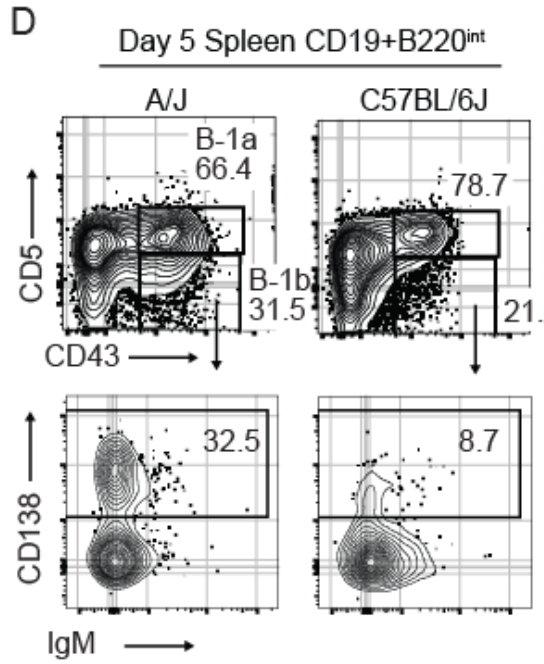

G

Day 5 PerC CD19+B220 ${ }^{\text {int }}$ CD43+ B-1b
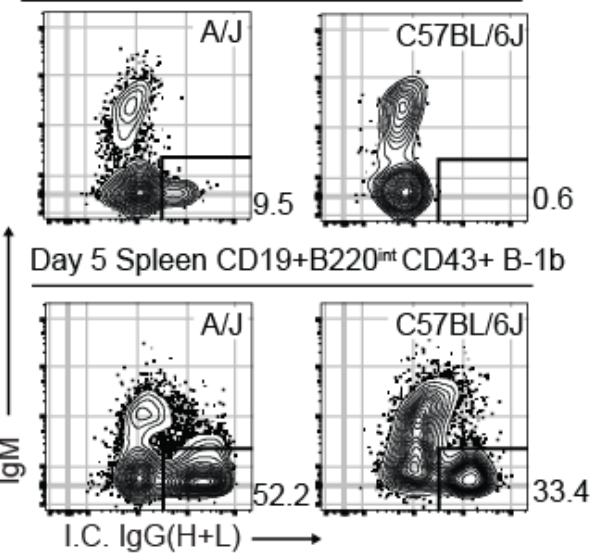

$\mathrm{H}$

\section{Day 5 CD19+B220 ${ }^{\text {int }}$ CD43+}

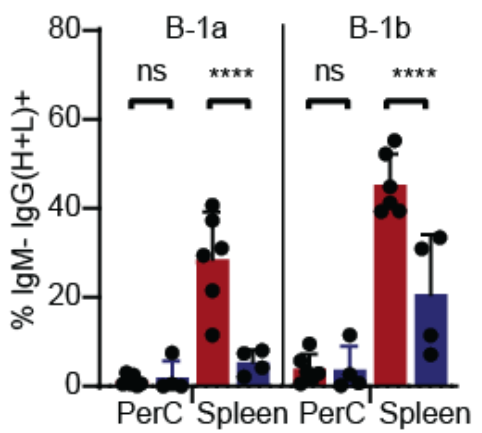

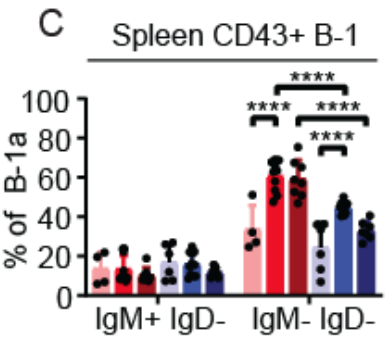

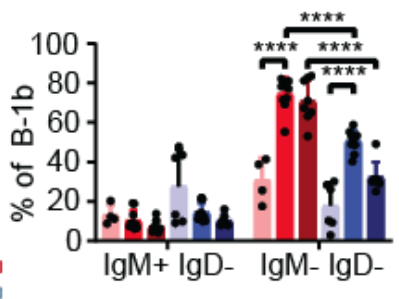

$\mathrm{F}$

AJ B-1b D5 AJ B-1b Chr B6 B-1b D5 B6 B-1b Chr

AJ B-1a D5

AJ B2 D5

B6 B2 D5

B6 B2 Chr

B6 B2 Naive

AJ B2 Chr

AJ B2 Naive

B6 B-1b Naive

AJ B-1a Naive

AJ B-1b Naive

AJ B-1a Chr

B6 B-1a Naive

B6 B-1a D5

B6 B-1a Chr

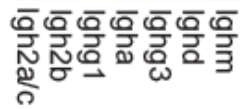

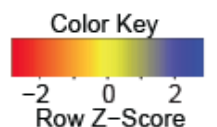

808 


\section{Figure 6. Evidence for enhanced B-1 cell activation in resistant $\mathbf{A} / \mathbf{J}$ mice.}

811 A) Gating strategies for identifying B-1 (CD19+ B220 int-neg $)$ and B-2 (CD19+ B220 hi) B cells. The

812 legend applies to panels C-H. B) Representative FACS plots of the CD11b+ peritoneal B-1 B cell

813 compartment in A/J and C57BL/6J (B6) mice at naïve, chronic (Chr), and 5 days (D5) post-

814 secondary infection with the GT1 strain. Numbers indicate the percent of cells that fall within the

815 indicated gate. Representative histograms of IgM surface expression and percent of cells that fall

816 within the $\mathrm{IgM}^{\mathrm{lo}}$ gate of CD5- B-1b cells from A/J (red) and C57BL/6J (blue) at the indicated time

817 points. C) Frequencies of splenic CD43+ B-1a (CD5+) or B-1b (CD5-) that are IgM+IgD- or IgM-

$818 \mathrm{IgD}$ - in $\mathrm{A} / \mathrm{J}$ and $\mathrm{C} 57 \mathrm{BL} / 6 \mathrm{~J}$ mice at the indicated infection states. D) Representative FACS plots of

819 splenic CD19+ B220 int-neg $\mathrm{B}$ cells stained for CD43 and CD5 in A/J and C57BL/6J mice at D5 of

820 secondary infection. Representative CD138 expression on CD5- CD43+ B-1b cells. E) Frequencies

821 of CD43+ splenic B-1a and B-1b cells from A/J and C57BL/6J mice that express BAFFR+, TACI+,

822 or CD138+ at the indicated infection states. F) Heatmap depicting the relative expression of all

823 Ighg transcripts from the indicated B cell population, mouse strain and infection state. G)

824 Representative FACS plots of intracellular $\operatorname{IgG}(\mathrm{H}+\mathrm{L})$ of B-1b cells, and $\mathrm{H})$ frequency of both

825 peritoneal and splenic B-1a and B-1b cells of A/J and C57BL/6J mice at day 5 of secondary

826 infection. For $\mathrm{C}, \mathrm{E}$ and $\mathrm{H}$, the cumulative average +SD from 2-4 experiments is plotted and each

827 dot represents the result from an individual mouse; P values calculated by 2-way ANOVA with

828 Tukey correction; **** $\mathrm{P}<0.0001$, *** $\mathrm{P}<0.001$, ** $\mathrm{P}<0.01, * \mathrm{P}<0.05$. 


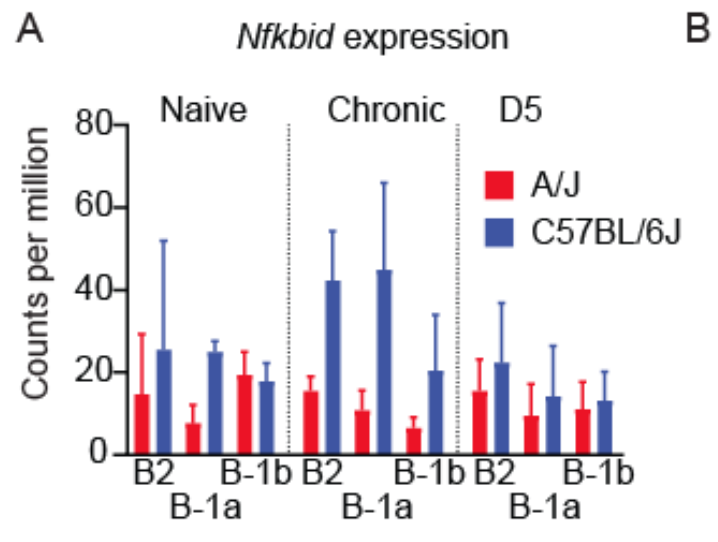

B Relative Nfkbid expression A/J B cells
PerC
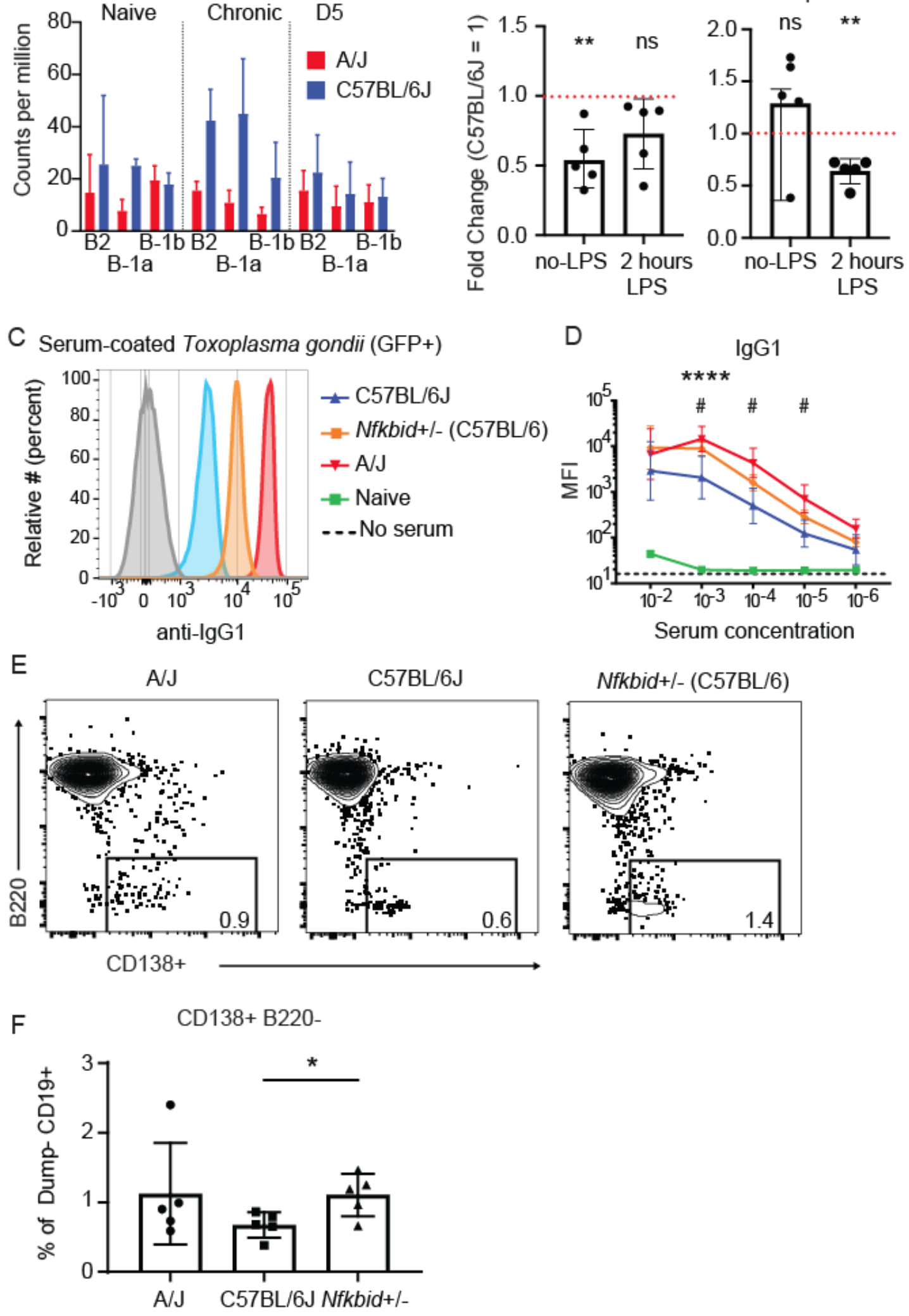


\section{Figure 7. Gene dosage of Nfkbid impacts parasite-specific IgG1 responses.}

832 A) Nfkbid expression in CPM (Counts per million) of 3'-Tag RNA-seq reads of the indicated B cell

833 populations obtained from $\mathrm{A} / \mathrm{J}$ and $\mathrm{C} 57 \mathrm{BL} / 6 \mathrm{~J}$ mice that were either naïve, chronically infected, or 834 on D5 of secondary infection with the type I GT1 strain. B) Enriched B cells from the PerC and 835 spleen were stimulated with LPS for $2 \mathrm{hrs}$ and Nfkbid transcripts were quantified by qPCR; ** $\mathrm{P}<$ 836 0.01, paired t-test. C) Representative histograms display the detection of parasite-specific $\operatorname{IgG} 1$ 837 bound to formaldehyde fixed GFP+ type I GT1 parasites; diluted serums (10 $)$ from C57BL/6J, $838 N$ Nfkid+/- (C57BL/6J x bumble F1), and A/J mice chronically infected with the type III CEP strain 839 were assayed. Anti-mouse IgG1 background staining in the absence of serum is shown. D) As in $840 \mathrm{C}$, but quantification of the parasite-specific IgG1 antibody isotype binding over a range of serum 841 concentrations is shown. Plotted is the cumulative average +/-SD of the MFI from 2-3 separate 842 experiments (C57BL/6J n=8; Nfkbid+/- $\mathrm{n}=7 ; \mathrm{A} / \mathrm{J} \mathrm{n}=8)$; significance was assessed by unpaired t843 tests and Holm-Sidak corrections comparing A/J vs C57BL/6J (*) or Nfkbid+/- vs C57BL/6J (\#);

$844 * * * * \mathrm{P}<0.0001,{ }^{\#} \mathrm{P}<0.05$. IgG1 staining was not significantly different between $\mathrm{A} / \mathrm{J}$ and Nfkbid+/845 serums. E) Representative FACS plots of the dump- CD19+ CD138+ plasmablast populations 846 within A/J, C57BL/6J and Nfkbid+/- mice at day 5 of secondary infection with type I GT1 parasites. 847 F) Frequency of B220- CD138+ plasmablasts of total live dump- CD19+ cells. Plotted is the 848 cumulative average $+/$-SD of 2 separate experiments ( $\mathrm{n}=5$ per mouse strain); significance was assessed by unpaired t-tests; $* \mathrm{P}<0.05$. 
851

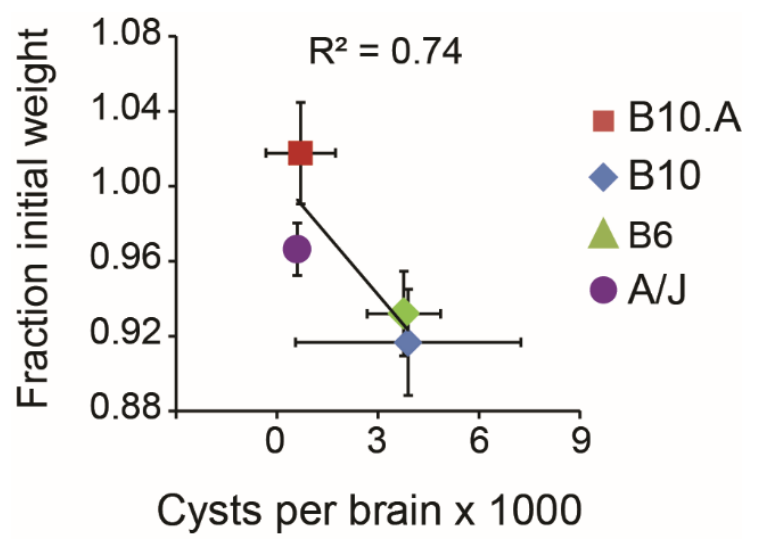

854 Figure S1. Cyst burden and weight during chronic infection with the low virulent type III 855 CEP strain correlates with the murine H-2 locus.

$856 \mathrm{~A} / \mathrm{J}, \mathrm{C} 57 \mathrm{BL} / 6 \mathrm{~J}(\mathrm{~B} 6), \mathrm{C} 57 \mathrm{BL} / 10 \mathrm{~J}$ (B10), and C57BL/10.AJ (B10.A) mice were injected with the

857 type III strain CEP hxgprt- and allowed to progress to chronic infection. Plotted (+/- SEM) is the

858 average cyst number (x 1000) in the brain vs. the average fraction of initial weight, where 1 is the

859 normalized weight on the day of type III injection; the regression value $\left(\mathrm{R}^{2}\right)$ is indicated. Results

860 are from 3 to 5 mice for cyst numbers (day 42 of chronic infection), and 5-12 mice for weight

861 measurements (day 30 of chronic infection) per mouse strain. 
Type I GT1 secondary infection

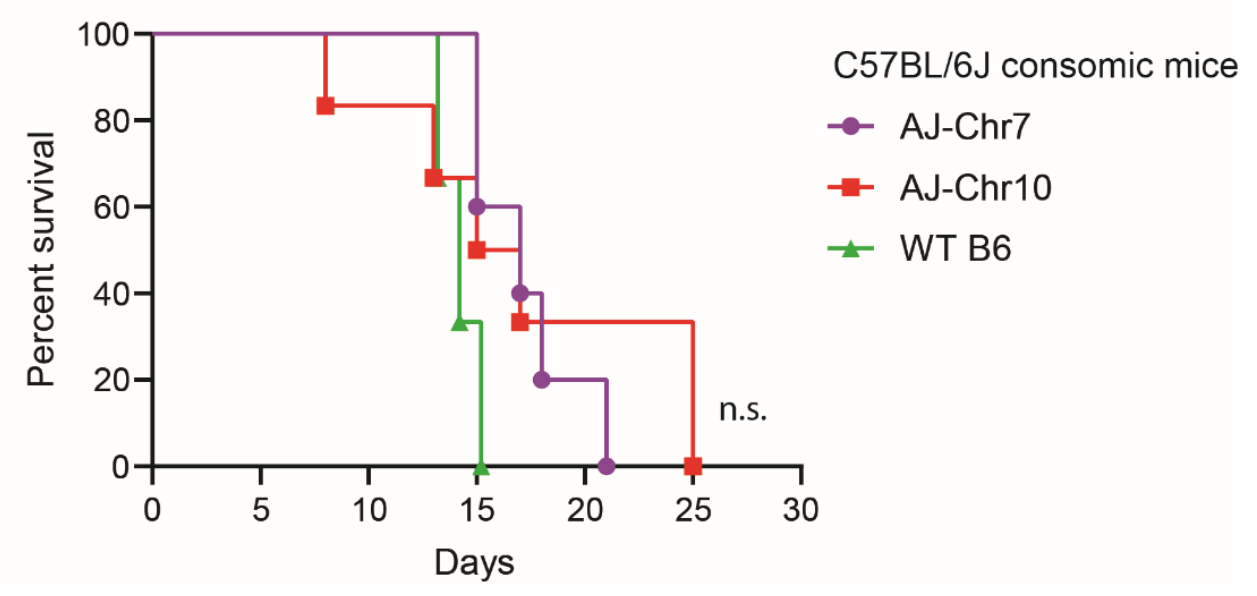

864 Figure S2. Consomic mice succumb to type I GT1 secondary infection.

865 Consomic mice of the C57BL/6J background with A/J chromosomal substitutions for chromosome

$8667\left(\mathrm{C} 57 \mathrm{BL} / 6 \mathrm{~J}-\mathrm{Chr} 7^{\mathrm{A} / \mathrm{J}} / \mathrm{NaJ}\right)$ or chromosome $10\left(\mathrm{C} 57 \mathrm{BL} / 6 \mathrm{~J}-\mathrm{Chr} 10^{\mathrm{A} / \mathrm{J}} / \mathrm{NaJ}\right)$ were infected with the

867 type III CEP hxgprt- strain and allowed to progress to chronic infection. Mice were then given a

868 secondary infection with the type I GT1 strain. Cumulative survival is shown for 2 independent

869 experiments (CSS7 n=5, CSS10 n=6); n.s., Mantel-Cox.

870 
A

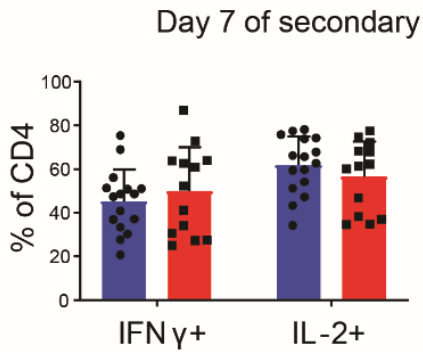

C57BL/6J - Bumble

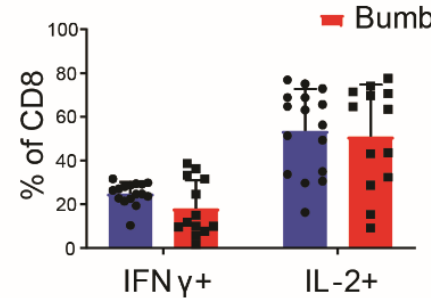

B

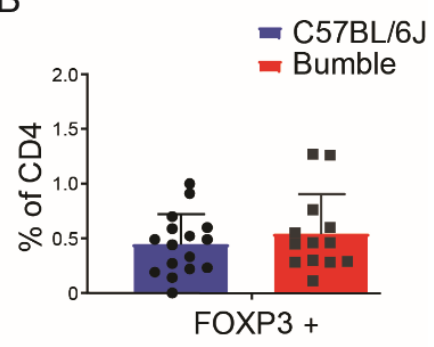

872 Figure S3. Bumble mice have intact $\mathbf{T}$ cell responses during secondary infection.

873 A) Peritoneal CD4 and CD8 T cells from bumble and C57BL/6J mice were assessed at day 7 of

874 secondary infection with the type I RH strain by an in vitro recall assay and assayed for intracellular

875 IFN $\gamma$ and IL-2. In brief, peritoneal cells were harvested and infected with live type I RH parasites

876 for $16 \mathrm{hrs}$. T cells were assessed for production of granzyme IFN $\gamma$, and IL-2 by intracellular staining

877 and FACS. B) Peritoneal T-regulatory cells (CD4+ CD25+ Foxp3+) were quantified at day 7 of

878 secondary infection with type I RH strain. Each dot represents the result from one mouse, and

879 plotted are cumulative averages +SD from 3 experiments; no significant differences were observed

880 between bumble and C57BL/6J mice by unpaired t-tests with the Holm-Sidak correction for

881 multiple comparisons. 


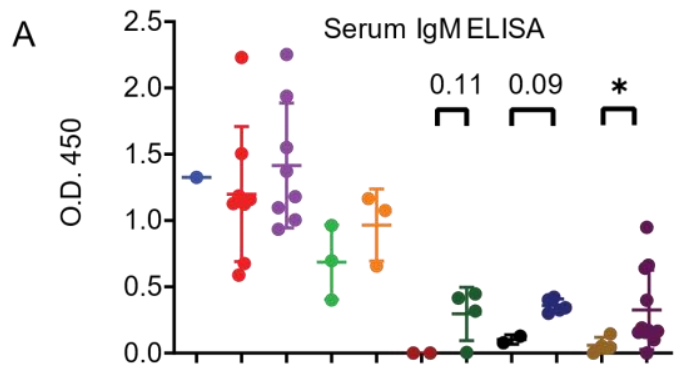

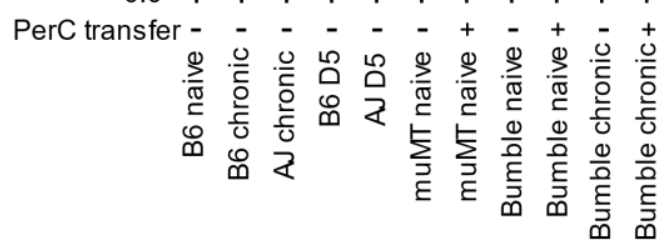

B
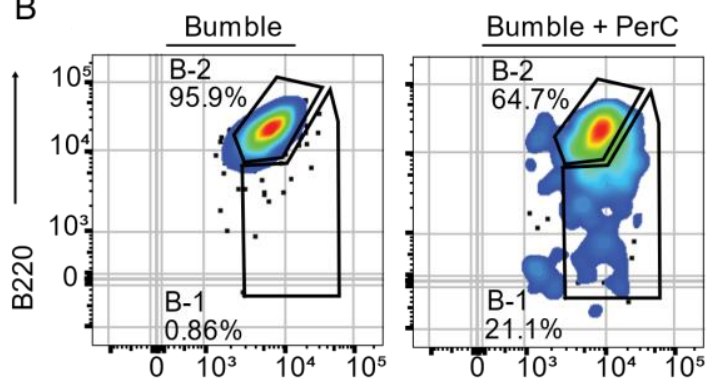

C Type III primary infection
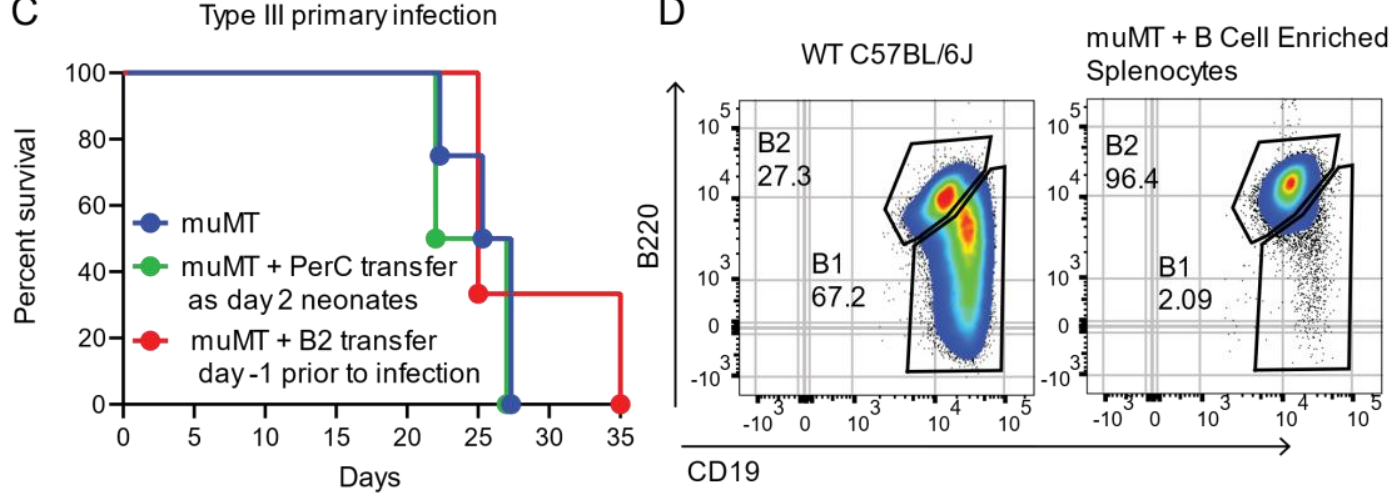

$\mathrm{E}$

WT C57BL/6J

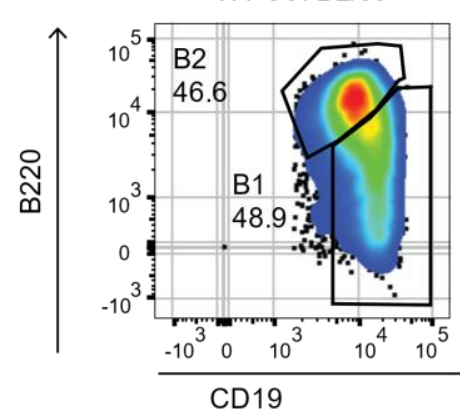

muMT
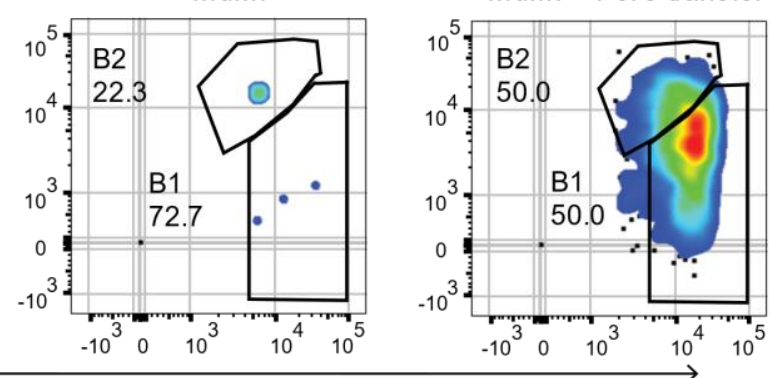

Figure S4. Assessing PerC reconstitutions by serum IgM ELISAs and flow cytometry, and survival of muMT mice.

A) Serum IgM from C57BL/6J, muMT, bumble, and A/J mice was measured by ELISA. Serum was harvested from mice either naïve, chronically infected with type III CEP strain, or on D5 postsecondary infection with type I GT1 T. gondii strain. PerC transfer (+) refers to mice adoptively 
889 transferred $5 \times 10^{6}$ total PerC cells as a day 2 neonate. Each dot represents the results from an

890 individual mouse, and plotted is the average +/-SD of the O.D. obtained at 450nm; *P<0.05,

891 unpaired two-tailed t-test. B) Bumble reconstitution of the peritoneal B-1 compartment after

892 neonatal PerC adoptive transfer. Representative FACS plots of peritoneal B-2 cells (B220 $0^{\text {high }}$

893 CD19+) and B-1 (B220 int-neg CD19+) cells from bumble mice with or without PerC adoptive

894 transfer. Shown are mice on day 20 of primary infection with the type III CEP strain. C) B cell

895 deficient muMT mice $(\mathrm{n}=3)$, muMT given WT PerC adoptive transfers as 2-day neonates then

896 allowed to reconstitute for 6-7 weeks into adulthood $(n=2)$, and muMT given B cell enriched

897 splenocytes $(n=3) 1$ day prior to infection with the type III CEP strain were assessed for survival.

898 D) muMT reconstitution of B-2 cell compartment, WT and muMT with B cell enriched splenocytes

899 (EasySep ${ }^{\mathrm{TM}}$ Mouse Pan-B Cell Isolation Kit, cat\# 19844) adoptively transferred 24 hrs earlier E)

900 muMT reconstitution of peritoneal B cell compartment after neonatal adoptive transfer.

901 Representative FACS plots of peritoneal B-2 cells (B220high CD19+) and B-1 B cells (B220int-

902 neg CD19+) from WT, and muMT mice or muMT mice with neonatal PerC adoptive transfer. For

903 D and E, uninfected mice are 6-8 weeks of age and numbers indicate the percent of cells that fall

904 within the depicted gate.

905 
A

B Bone marrow chimeric mice

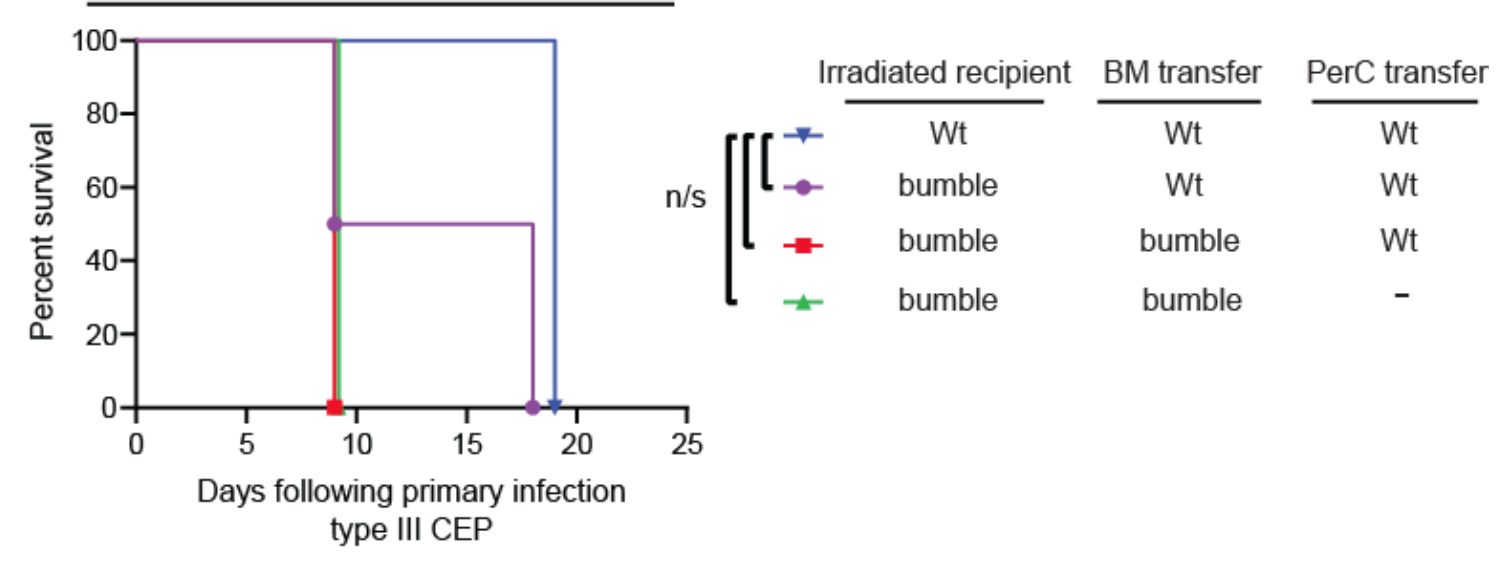

B

Bone marrow chimeric mice
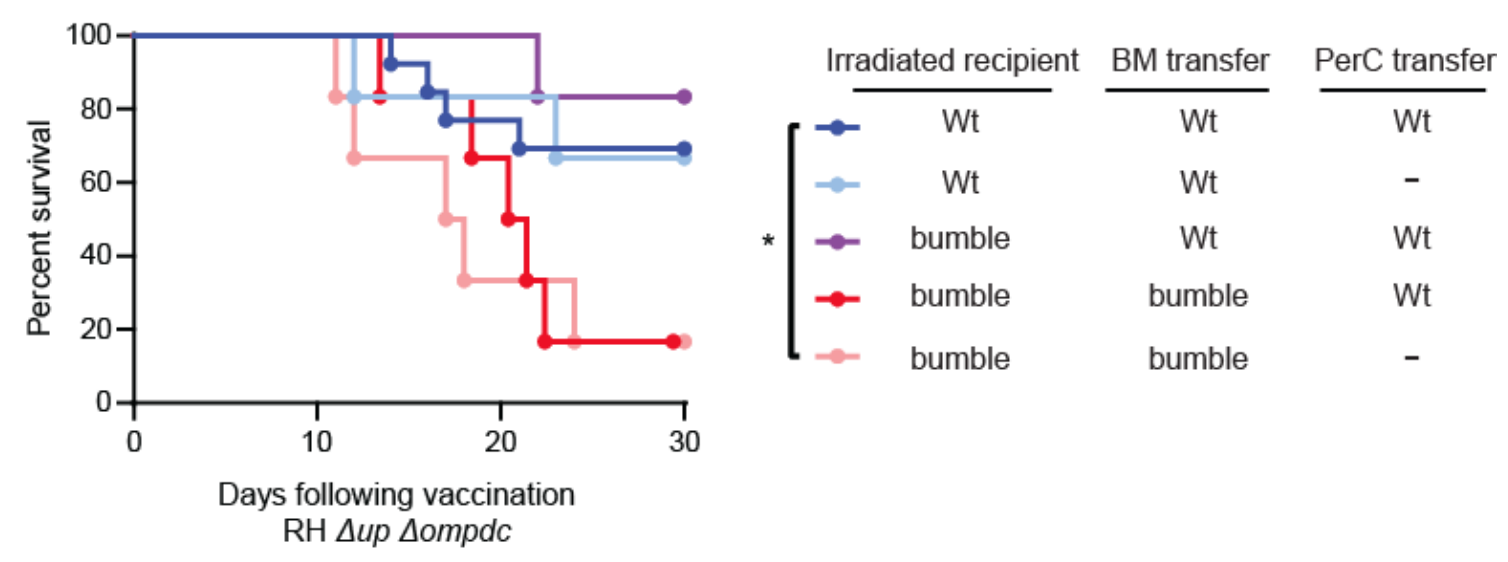

$\mathrm{RH} \Delta u p \Delta o m p d c$

907 Figure S5. Bone marrow chimeric mice fail to survive primary infection but exhibit improved

908 survival to vaccine strains.

909 A) Survival of the indicated bone marrow (BM) chimeras infected with the type III CEP T. gondii

910 strain are plotted from a single experiment ( $\mathrm{n}=2$ for bumble recipients per condition; $\mathrm{n}=1$ for

911 C57BL/6J recipients); n.s., Mantel-Cox. B) Survival of the indicated BM chimeras vaccinated (10

912 i.p.) with the uracil auxotroph strain, Rh $\Delta u p \Delta o m p d c$. Results are cumulative from 2-3 separate

913 transfers and vaccinations; ( $\mathrm{n}=4-9$ per condition). 
A

PerC CD8 T cells

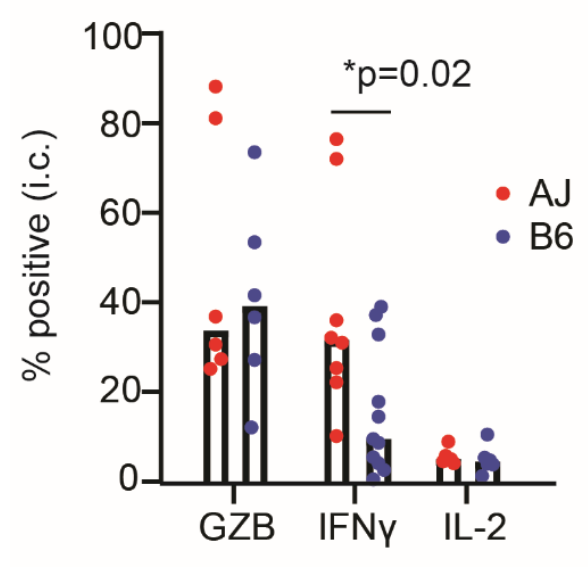

B

Spl CD8 T cells

915

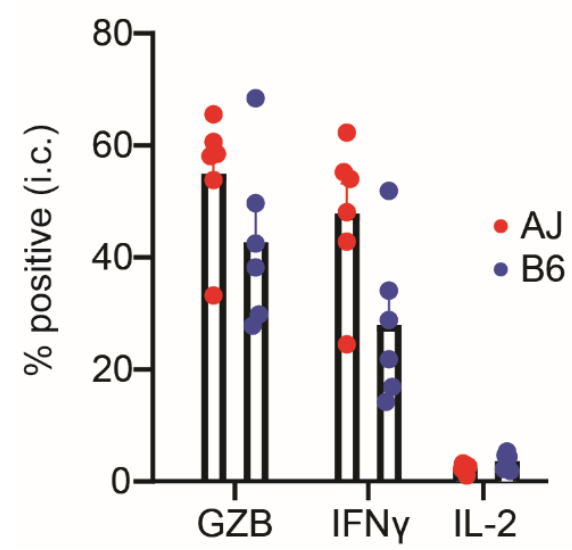

PerC CD4 T cells

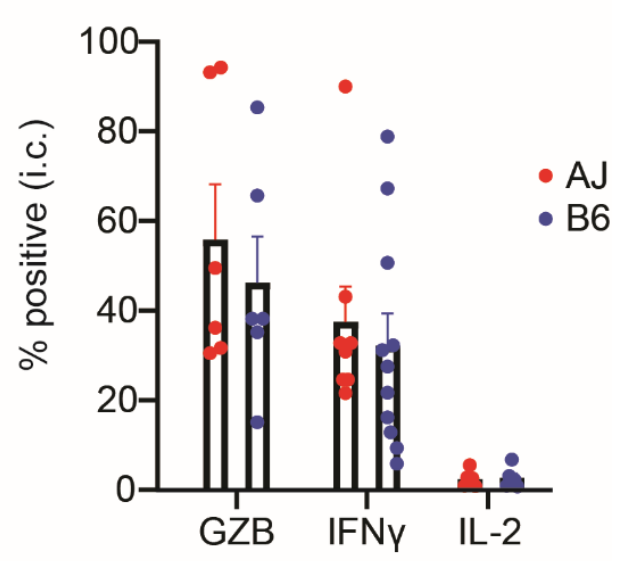

Spl CD4 T cells

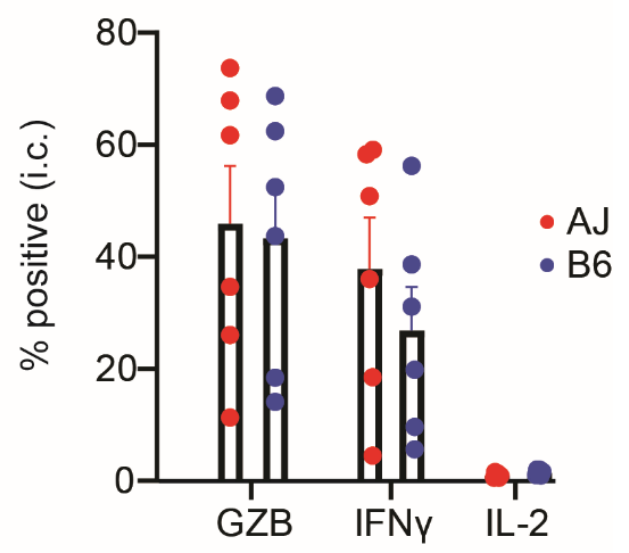

916 Figure S6. CD8 T cell IFN $\gamma$ frequencies are increased in resistant $\mathbf{A} / \mathbf{J}$ mice.

917 A) Peritoneal and B) splenic cells were harvested from A/J and C57BL6/J mice chronically infected

918 with type III CEP T. gondii strain, and infected with live type I parasites for $16 \mathrm{hrs}$. T cells were

919 assessed for production of granzyme B (GZB), IFN $\gamma$, and IL-2 by intracellular staining and FACS.

920 The average frequency +/-SD of positive staining CD4+ or CD8+ T cells (CD3+ CD19-) and

921 cumulative results from 2-3 experiments ( $\mathrm{AJ} \mathrm{n}=8, \mathrm{C} 57 \mathrm{BL6} / \mathrm{J} \mathrm{n}=11$ ) are shown; * $\mathrm{P}<0.05$, unpaired

922 two-tailed t-test. 
bioRxiv preprint doi: https://doi.org/10.1101/2020.06.26.174151; this version posted May 28, 2021. The copyright holder for this preprint (which was not certified by peer review) is the author/funder, who has granted bioRxiv a license to display the preprint in perpetuity. It is made available under aCC-BY-NC-ND 4.0 International license.

A Four fold induced genes in A/J B-1b cells Day 5 vs. Naive

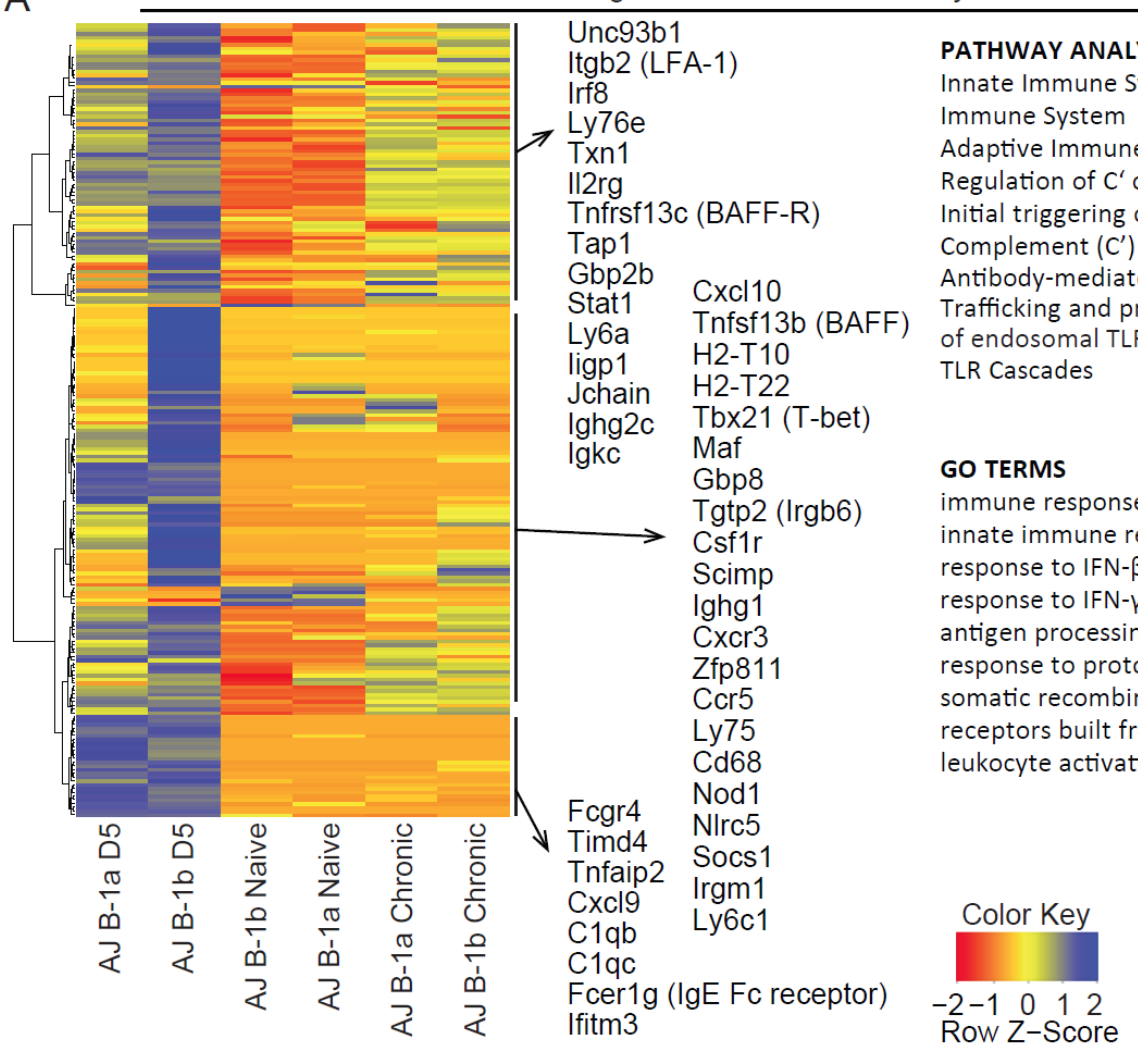

B

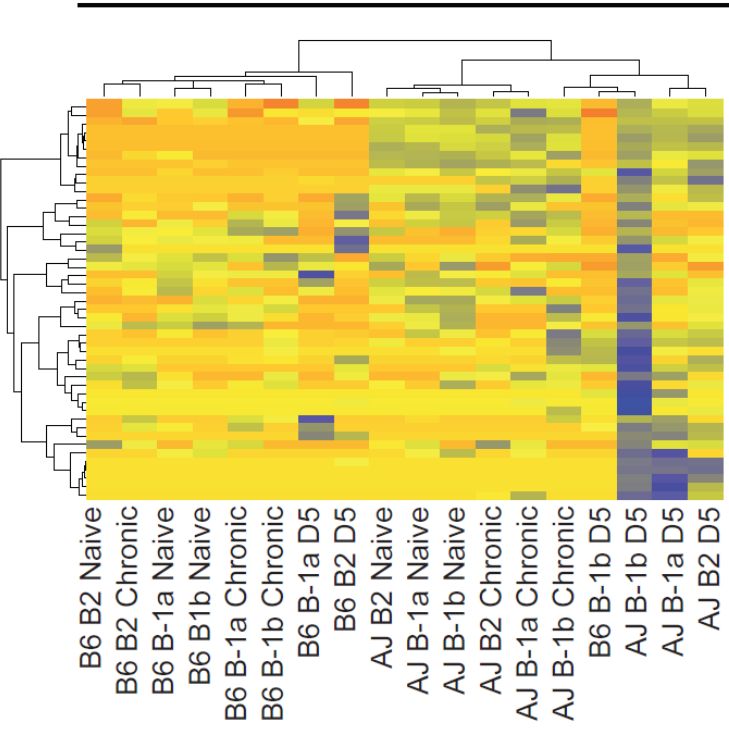

C

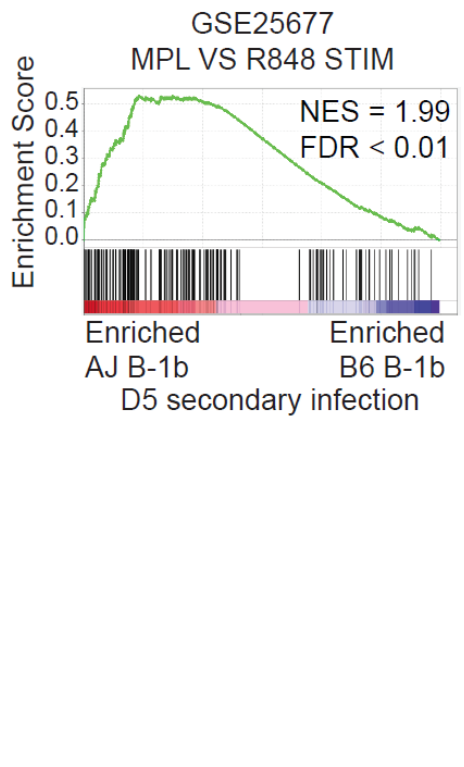


926 Figure S7. Genes uniquely induced in B-1b cells on day 5 of secondary infection in resistant

$927 \quad \mathbf{A} / \mathbf{J}$ mice.

928 Transcriptomic analysis of peritoneal B-1a (CD19+ B220 int-neg CD11b+ CD5+), B-1b (CD19+ 929 B220 int-neg $C D 11 b+C D 5-)$ and B-2 (CD19+ B220 ${ }^{\text {hi }}$ CD11b- CD5-) B cells from A/J and C57BL/6J

930 mice was performed using 3'-Tag RNA sequencing. A) Genes that were differentially upregulated

931 in B-1b cells on day 5 of secondary infection compared to naïve mice in the $\mathrm{A} / \mathrm{J}$ genetic background.

$932 \mathrm{P}$ values of differentially expressed genes were calculated using the Benjamini-Hochberg 933 adjustment for false discovery rate, and only those genes that survived significance were included 934 in the heatmap. For comparison, all B-1 compartments in A/J mice are shown for this gene set. A/J 935 B-1 Pathway and GO term enrichment was assessed on the genes presented in the heatmap in A. P 936 values for enrichment analysis were adjusted with the Holm-Bonferroni correction. B) A cluster of 937 genes found to be differentially induced in B-1b cells in A/J compared to C57BL/6J mice on day 5 938 of secondary infection are plotted as a heat map. C) Gene set enrichment analysis of the rank939 ordered list of differentially expressed genes between A/J and C57BL/6J B-1b cells at D5 of 940 secondary infection. Gene set depicted was in the top 10 gene sets ranked by false discovery rate 941 (FDR) after investigating MSigDB's C7: immunologic signatures collection. Enrichment score is 942 the degree of overrepresentation of a gene set at the top or bottom of a ranked list. NES is the 943 enrichment score after normalizing for gene set size. 


\begin{tabular}{|l|c|c|c|}
\hline \multicolumn{1}{|c|}{ Mouse Strain } & Chronic Infection & Secondary Infection & 1 Heterologous Brain Coinfection? \\
\hline \hline C57BL/10 & CEP $x$ gprt- & GUYMAT & $1 / 1$ \\
\hline Cumulative average C57BL/10 & & $1 / 1=100 \%$ \\
\hline C57BL/10.A & CEP hxgprt- & TgCATBr5 & $2 / 2$ \\
C57BL/10.A & CEP hxgprt- & GUYMAT & $2 / 2$ \\
C57BL/10.A & CEP hxgprt- & MAS & $1 / 2$ \\
C57BL/10.A & CEP hxgprt- & FOU & $0 / 1$ \\
\hline Cumulative average C57BL/10.A & & $5 / 7=71 \%$ \\
\hline A/J & CEP hxgprt- & GUYMAT & $0 / 4$ \\
A/J & CEP hxgprt- & TgCATBr5 & $0 / 5$ \\
A/J & CEP hxgprt- & GUYDOS & $4 / 5$ \\
A/J & CEP hxgprt- & VAND & $4 / 6$ \\
A/J & CEP hxgprt- & FOU & $1 / 5$ \\
A/J & CEP hxgprt- & GPHT & $0 / 5$ \\
A/J & CEP hxgprt- & MAS & $0 / 5$ \\
\hline Cumulative average A/J & & $9 / 35=26 \%$ \\
\hline
\end{tabular}

945 Table S1. Virulent strains of Toxoplasma gondii superinfect genetically resistant hosts.

946 CEP hxgprt- chronically infected C57BL/10, C57BL/10.A, and A/J mice were given a secondary

947 infection with the indicated atypical $T$. gondii strain; then, 35-45 days after secondary infection,

948 brains from surviving mice were homogenized in PBS and used to inoculate HFF monolayers. The

949 resultant parasite cultures were then tested for the presence of the secondary infection strain;

950 numerator $=$ number of mice tested positive for secondary infection strain in the brain; denominator

$951=$ number of mice that exhibited parasite growth in the HFF monolayer prior to drug selection.

$952{ }^{1}$ Parasite growth was observed in mycophenolic acid / xanthine medium, which selects for parasites

953 encoding a functional $H X G P R T$ gene (i.e. the challenging atypical strains) and kills the primary

954 infection CEP hxgprt-strain. 


\begin{tabular}{|c|c|c|c|}
\hline $\begin{array}{c}\text { Recombinant Inbred } \\
\text { Strain }\end{array}$ & $\begin{array}{l}\text { Type III CEP Primary } \\
\text { Infection Survival }\end{array}$ & $\begin{array}{l}\text { Type I GT1 Secondary } \\
\text { Infection Survival }\end{array}$ & $\begin{array}{c}{ }^{1} \text { Heterologous Brain } \\
\text { Coinfection? }\end{array}$ \\
\hline 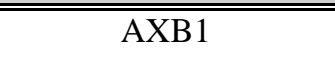 & 100 & 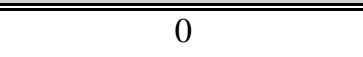 & N/A \\
\hline AXB2 & 100 & 100 & $0 / 2$ \\
\hline AXB4 & 0 & N/A & N/A \\
\hline AXB5 & 50 & 100 & $1 / 1$ \\
\hline AXB6 & 0 & N/A & N/A \\
\hline AXB8 & 100 & 50 & $1 / 1$ \\
\hline AXB10 & 0 & N/A & N/A \\
\hline AXB12 & 100 & 100 & $2 / 2$ \\
\hline AXB13 & 0 & N/A & N/A \\
\hline AXB15 & 100 & 100 & $1 / 2$ \\
\hline AXB19 & 100 & 0 & N/A \\
\hline AXB23 & 100 & 0 & N/A \\
\hline AXB24 & 100 & 0 & N/A \\
\hline BXA1 & 50 & 0 & N/A \\
\hline BXA2 & 100 & 0 & N/A \\
\hline BXA4 & 100 & 100 & $0 / 1$ \\
\hline BXA7 & 100 & 0 & N/A \\
\hline BXA8 & 100 & 100 & $2 / 2$ \\
\hline BXA11 & 100 & 0 & N/A \\
\hline BXA12 & 100 & 100 & $1 / 1$ \\
\hline BXA13 & 100 & 100 & $0 / 1$ \\
\hline BXA14 & 100 & 0 & N/A \\
\hline BXA16 & 100 & 0 & N/A \\
\hline BXA24 & 100 & 50 & N/A \\
\hline BXA25 & 100 & 100 & $1 / 2$ \\
\hline BXA26 & 100 & 100 & $0 / 2$ \\
\hline Cumulative Average & $82.6 \%$ & $50 \%$ & $9 / 17=52.9 \%$ \\
\hline
\end{tabular}


955 Table S2. Primary and secondary infection survival of recombinant inbred mice (AxB;BxA).

95626 strains $(\mathrm{n}=2)$ from the RI $(\mathrm{AxB} ; \mathrm{BxA})$ panel were infected with $10^{4}$ type III avirulent CEP

957 hxgprt- T. gondii parasites; then, 35 days later, mice were challenged with $5 \times 10^{4}$ virulent type I

958 GT1 T. gondii parasites. Primary and secondary infection survival percentages are indicated. 35-

95945 days after secondary challenge, brains from the surviving RI mice were homogenized in PBS

960 and used to inoculate HFF monolayers. The resultant parasite cultures were then tested for the

961 presence of the challenging strain; numerator $=$ number of mice tested positive for secondary

962 infection strain in the brain; denominator = number of mice that exhibited parasite growth in the

963 HFF monolayer prior to drug selection. Some surviving mice failed to generate parasite positive

964 cultures.

$965{ }^{1}$ Parasite growth was observed in mycophenolic acid / xanthine medium, which selects for GT1

966 parasites (the challenging strain) encoding the endogenous $H X G P R T$ gene and against the primary

967 infection CEP hxgprt- strain.

968

969 
Dataset S1. Polymorphic genes between A/J and C57BL/6J encoded within the four QTLs

972 For each of the four QTLs that define secondary infection immunity to T. gondii, a list of all genes

973 that have a DNA polymorphism between A/J and C5BL/6J mice, and are encoded within the QTL

974 boundaries defined by the maximal genetic marker (real or imputed markers inferred in r/QTL) and

975 the two flanking markers on either side; LOD scores and position are indicated. For each gene, its

976 location and unique identifiers are listed, as well as the number and class of small nucleotide

977 polymorphism (SNP) between A/J and C57BL/6J are shown. Total number of SNPs for each gene

978 were also tallied ('Sum mutation'), and in bold are genes who's SNPs are two standard deviations

979 greater than the average SNP for that class within the QTL region. In these QTL regions, there were

980 also 476 (chr7), 88 (chr10), 40 (chr11) and 375 SNPs (chr17) that did not associate with any gene

981 in the QTL boundaries. UTR, untranslated region; 'Region SNP', SNPs that are $+/-2 \mathrm{~kb}$ of the gene

982 boundaries. Data obtained from Mouse Genome Informatics (MGI) (informatics.jax.org), and each

983 locus is in a separate tab.

985 Dataset S2. Transcriptomic analysis of B cells responding to Toxoplasma gondii infection.

986 Table of genes included (threshold of >=5 CPM in any sample) in differential gene expression 987 analysis. For each gene the Ensembl ID, MGI ID, gene symbol and descriptions are listed. The 988 CPM from 3 samples of peritoneal B-1a, B-1b, and B-2 at naïve (N), chronic (Ch), and day 5 (D5) 989 of secondary infection in both $\mathrm{A} / \mathrm{J}(\mathrm{AJ})$ and C57BL/6J (B6) mice are given. The average CPM was 990 calculated for each set of samples and average counts less than 5 CPM were raised to 5 to reduce 991 the effect of low expression genes in further analysis. The $\log 2$ fold change (FC) of gene expression 992 was calculated using the average CPM for each cell type (B-1a, B-1b, and B-2) of each strain (A/J 993 and C57BL/6J) as they progressed from naïve to chronic infection or chronic to D5 secondary 994 infection. The Log2 FC was also calculated from naïve to D5 of secondary infection. The Log2 FC 
between $\mathrm{A} / \mathrm{J}$ and $\mathrm{C} 57 \mathrm{BL} / 6 \mathrm{~J}$ was calculated for each cell type. Genes were then ranked by the number of comparisons that exhibited greater than $4 \mathrm{FC}$ by the indicated comparison.

\section{REFERENCES}

1. Sacks DL. Vaccines against tropical parasitic diseases: a persisting answer to a persisting problem. Nat Immunol. 2014;15: 403-405. doi: 10.1038/ni.2853 [doi].

1002

1003

1004

1005

1006

1007

1008

1009

1010

1011

1012

1013

1014

1015

1016

1017

1018

1019

1020

1021

1022

1023

1024

1025

1026

1027

1028
2. Lorenzi H, Khan A, Behnke MS, Namasivayam S, Swapna LS, Hadjithomas M, et al. Local admixture of amplified and diversified secreted pathogenesis determinants shapes mosaic Toxoplasma gondii genomes. Nat Commun. 2016;7: 10147. doi: 10.1038/ncomms10147 [doi].

3. Howe DK, Sibley LD. Toxoplasma gondii comprises three clonal lineages: correlation of parasite genotype with human disease. J Infect Dis. 1995;172: 1561-1566.

4. Grigg ME, Ganatra J, Boothroyd JC, Margolis TP. Unusual Abundance of Atypical Strains Associated with Human Ocular Toxoplasmosis. J Infect Dis. 2001;184: 633 639. doi: $10.1086 / 322800$.

5. Khan A, Jordan C, Muccioli C, Vallochi AL, Rizzo LV, Belfort R,Jr, et al. Genetic divergence of Toxoplasma gondii strains associated with ocular toxoplasmosis, Brazil. Emerg Infect Dis. 2006;12: 942-949.

6. McLeod R, Boyer KM, Lee D, Mui E, Wroblewski K, Karrison T, et al. Prematurity and severity are associated with Toxoplasma gondii alleles (NCCCTS, 1981-2009). Clin Infect Dis. 2012;54: 1595-1605. doi: 10.1093/cid/cis258 [doi].

7. Suzuki Y, Remington JS. The effect of anti-IFN-gamma antibody on the protective effect of Lyt-2+ immune T cells against toxoplasmosis in mice. J Immunol. 1990;144: 1954-1956.

8. Gazzinelli RT, Hakim FT, Hieny S, Shearer GM, Sher A. Synergistic role of CD4+ and CD8+ T lymphocytes in IFN-gamma production and protective immunity induced by an attenuated Toxoplasma gondii vaccine. J Immunol. 1991;146: 286-292.

9. Gigley JP, Fox BA, Bzik DJ. Cell-mediated immunity to Toxoplasma gondii develops primarily by local Th1 host immune responses in the absence of parasite replication. J Immunol. 2009;182: 1069-1078. doi: 182/2/1069 [pii].

10. Casciotti L, Ely KH, Williams ME, Khan IA. CD8(+)-T-cell immunity against Toxoplasma gondii can be induced but not maintained in mice lacking conventional CD4(+) T cells. Infect Immun. 2002;70: 434-443. doi: 10.1128/iai.70.2.434-443.2002 [doi].

11. Johnson LL, Sayles PC. Deficient humoral responses underlie susceptibility to Toxoplasma gondii in CD4-deficient mice. Infect Immun. 2002;70: 185-191. 
12. Chen M, Mun HS, Piao LX, Aosai F, Norose K, Mohamed RM, et al. Induction of protective immunity by primed B-1 cells in Toxoplasma gondii -infected B cell-deficient mice. Microbiol Immunol. 2003;47: 997-1003.

13. Kang H, Remington JS, Suzuki Y. Decreased resistance of B cell-deficient mice to infection with Toxoplasma gondii despite unimpaired expression of IFN-gamma, TNF-alpha, and inducible nitric oxide synthase. J Immunol. 2000;164: 2629-2634. doi: ji_v164n5p2629 [pii].

14. Sayles PC, Gibson GW, Johnson LL. B cells are essential for vaccination-induced resistance to virulent Toxoplasma gondii. Infect Immun. 2000;68: 1026-1033.

15. Couper KN, Roberts CW, Brombacher F, Alexander J, Johnson LL. Toxoplasma gondiispecific immunoglobulin $\mathrm{M}$ limits parasite dissemination by preventing host cell invasion. Infect Immun. 2005;73: 8060-8068. doi: 73/12/8060 [pii].

16. Mineo JR, McLeod R, Mack D, Smith J, Khan IA, Ely KH, et al. Antibodies to Toxoplasma gondii major surface protein (SAG-1, P30) inhibit infection of host cells and are produced in murine intestine after peroral infection. J Immunol. 1993;150: 3951-3964.

17. Joiner KA, Fuhrman SA, Miettinen HM, Kasper LH, Mellman I. Toxoplasma gondii: fusion competence of parasitophorous vacuoles in Fc receptor-transfected fibroblasts. Science. 1990;249: 641-646.

18. Glatman Zaretsky A, Silver JS, Siwicki M, Durham A, Ware CF, Hunter CA. Infection with Toxoplasma gondii alters lymphotoxin expression associated with changes in splenic architecture. Infect Immun. 2012;80: 3602-3610. doi: 10.1128/IAI.00333-12 [doi].

19. Stumhofer JS, Silver JS, Hunter CA. IL-21 is required for optimal antibody production and T cell responses during chronic Toxoplasma gondii infection. PLoS One. 2013;8: e62889. doi: 10.1371/journal.pone.0062889 [doi].

20. Smith FL, Baumgarth N. B-1 cell responses to infections. Curr Opin Immunol. 2019;57: 2331. doi: S0952-7915(18)30151-1 [pii].

21. Alugupalli KR, Leong JM, Woodland RT, Muramatsu M, Honjo T, Gerstein RM. B1b lymphocytes confer T cell-independent long-lasting immunity. Immunity. 2004;21: 379-390. doi: 10.1016/j.immuni.2004.06.019 [doi].

22. Yang Y, Ghosn EE, Cole LE, Obukhanych TV, Sadate-Ngatchou P, Vogel SN, et al. Antigenspecific antibody responses in B-1a and their relationship to natural immunity. Proc Natl Acad Sci U S A. 2012;109: 5382-5387. doi: 10.1073/pnas.1121631109 [doi].

23. Pape KA, Taylor JJ, Maul RW, Gearhart PJ, Jenkins MK. Different B cell populations mediate early and late memory during an endogenous immune response. Science. 2011;331: 1203-1207. doi: 10.1126/science.1201730 [doi].

24. Krishnamurty AT, Thouvenel CD, Portugal S, Keitany GJ, Kim KS, Holder A, et al. Somatically Hypermutated Plasmodium-Specific IgM(+) Memory B Cells Are Rapid, Plastic, Early Responders upon Malaria Rechallenge. Immunity. 2016;45: 402-414. doi: 10.1016/j.immuni.2016.06.014 [doi]. 
25. Jensen KD, Camejo A, Melo MB, Cordeiro C, Julien L, Grotenbreg GM, et al. Toxoplasma gondii superinfection and virulence during secondary infection correlate with the exact ROP5/ROP18 allelic combination. MBio. 2015;6: 2280. doi: 10.1128/mBio.02280-14 [doi].

26. Splitt SD, Souza SP, Valentine KM, Castellanos BE, Curd AB, Hoyer KK, et al. PD-L1, TIM-3, and CTLA-4 blockade fail to promote resistance to secondary infection with virulent strains of Toxoplasma gondii. Infect Immun. 2018. doi: IAI.00459-18 [pii].

27. McLeod R, Skamene E, Brown CR, Eisenhauer PB, Mack DG. Genetic regulation of early survival and cyst number after peroral Toxoplasma gondii infection of $\mathrm{A} \times \mathrm{B} / \mathrm{B} \times \mathrm{A}$ recombinant inbred and B10 congenic mice. J Immunol. 1989;143: 3031-3034.

28. Brown CR, Hunter CA, Estes RG, Beckmann E, Forman J, David C, et al. Definitive identification of a gene that confers resistance against Toxoplasma cyst burden and encephalitis. Immunology. 1995;85: 419-428.

29. Hassan MA, Jensen KD, Butty V, Hu K, Boedec E, Prins P, et al. Transcriptional and Linkage Analyses Identify Loci that Mediate the Differential Macrophage Response to Inflammatory Stimuli and Infection. PLoS Genet. 2015;11: e1005619. doi: 10.1371/journal.pgen.1005619 [doi].

30. Schuster M, Annemann M, Plaza-Sirvent C, Schmitz I. Atypical IkappaB proteins - nuclear modulators of NF-kappaB signaling. Cell Commun Signal. 2013;11: 23-23. doi: 10.1186/1478811X-11-23 [doi].

31. Touma M, Keskin DB, Shiroki F, Saito I, Koyasu S, Reinherz EL, et al. Impaired B cell development and function in the absence of IkappaBNS. J Immunol. 2011;187: 3942-3952. doi: 10.4049/jimmunol.1002109 [doi].

32. Arnold CN, Pirie E, Dosenovic P, McInerney GM, Xia Y, Wang N, et al. A forward genetic screen reveals roles for Nfkbid, Zeb1, and Ruvbl2 in humoral immunity. Proc Natl Acad Sci U S A. 2012;109: 12286-12293. doi: 10.1073/pnas.1209134109 [doi].

33. Pedersen GK, Adori M, Stark JM, Khoenkhoen S, Arnold C, Beutler B, et al. Heterozygous Mutation in IkappaBNS Leads to Reduced Levels of Natural IgM Antibodies and Impaired Responses to T-Independent Type 2 Antigens. Front Immunol. 2016;7: 65. doi: 10.3389/fimmu.2016.00065 [doi].

34. Khoenkhoen S, Erikson E, Adori M, Stark JM, Scholz JL, Cancro MP, et al. TACI expression and plasma cell differentiation are impaired in the absence of functional IkappaBNS. Immunol Cell Biol. 2019;97: 485-497. doi: 10.1111/imcb.12228 [doi].

35. Touma M, Antonini V, Kumar M, Osborn SL, Bobenchik AM, Keskin DB, et al. Functional role for I kappa BNS in T cell cytokine regulation as revealed by targeted gene disruption. $\mathrm{J}$ Immunol. 2007;179: 1681-1692. doi: 179/3/1681 [pii].

36. Schuster M, Glauben R, Plaza-Sirvent C, Schreiber L, Annemann M, Floess S, et al. IkappaB(NS) protein mediates regulatory T cell development via induction of the Foxp3 transcription factor. Immunity. 2012;37: 998-1008. doi: 10.1016/j.immuni.2012.08.023 [doi]. 
37. Kuwata H, Matsumoto M, Atarashi K, Morishita H, Hirotani T, Koga R, et al. IkappaBNS inhibits induction of a subset of Toll-like receptor-dependent genes and limits inflammation. Immunity. 2006;24: 41-51. doi: S1074-7613(05)00377-8 [pii].

38. Berthier-Vergnes O, El Kharbili M, de la Fouchardiere A, Pointecouteau T, Verrando P, Wierinckx A, et al. Gene expression profiles of human melanoma cells with different invasive potential reveal TSPAN8 as a novel mediator of invasion. Br J Cancer. 2011;104: 155-165. doi: 10.1038/sj.bjc.6605994 [doi].

39. Zhao K, Wang Z, Hackert T, Pitzer C, Zoller M. Tspan8 and Tspan8/CD151 knockout mice unravel the contribution of tumor and host exosomes to tumor progression. J Exp Clin Cancer Res. 2018;37: 312-6. doi: 10.1186/s13046-018-0961-6 [doi].

40. Kim CC, Baccarella AM, Bayat A, Pepper M, Fontana MF. FCRL5(+) Memory B Cells Exhibit Robust Recall Responses. Cell Rep. 2019;27: 1446-1460.e4. doi: S2211-1247(19)30484$\mathrm{X}$ [pii].

41. Pedersen GK, Adori M, Khoenkhoen S, Dosenovic P, Beutler B, Karlsson Hedestam GB. B1a transitional cells are phenotypically distinct and are lacking in mice deficient in IkappaBNS. Proc Natl Acad Sci U S A. 2014;111: 4119. doi: 10.1073/pnas.1415866111 [doi].

42. Baumgarth N, Jager GC, Herman OC, Herzenberg LA. CD4+ T cells derived from B celldeficient mice inhibit the establishment of peripheral B cell pools. Proc Natl Acad Sci U S A. 2000;97: 4766-4771. doi: 97/9/4766 [pii].

43. Choi YS, Baumgarth N. Dual role for B-1a cells in immunity to influenza virus infection. J Exp Med. 2008;205: 3053-3064. doi: 10.1084/jem.20080979 [doi].

44. Kreuk LS, Koch MA, Slayden LC, Lind NA, Chu S, Savage HP, et al. B cell receptor and Toll-like receptor signaling coordinate to control distinct B-1 responses to both self and the microbiota. Elife. 2019;8: 10.7554/eLife.47015. doi: 10.7554/eLife.47015 [doi].

45. Lalor PA, Herzenberg LA, Adams S, Stall AM. Feedback regulation of murine Ly-1 B cell development. Eur J Immunol. 1989;19: 507-513. doi: 10.1002/eji.1830190315 [doi].

46. Kantor AB, Stall AM, Adams S, Herzenberg LA, Herzenberg LA. Differential development of progenitor activity for three B-cell lineages. Proc Natl Acad Sci U S A. 1992;89: 3320-3324. doi: 10.1073/pnas.89.8.3320 [doi].

47. Yap GS, Sher A. Effector cells of both nonhemopoietic and hemopoietic origin are required for interferon (IFN)-gamma- and tumor necrosis factor (TNF)-alpha-dependent host resistance to the intracellular pathogen, Toxoplasma gondii. J Exp Med. 1999;189: 1083-1092. doi: 10.1084/jem.189.7.1083 [doi].

48. Ha SA, Tsuji M, Suzuki K, Meek B, Yasuda N, Kaisho T, et al. Regulation of B1 cell migration by signals through Toll-like receptors. J Exp Med. 2006;203: 2541-2550. doi: jem.20061041 [pii]. 
49. Waffarn EE, Hastey CJ, Dixit N, Soo Choi Y, Cherry S, Kalinke U, et al. Infection-induced type I interferons activate CD11b on B-1 cells for subsequent lymph node accumulation. Nat Commun. 2015;6: 8991. doi: 10.1038/ncomms9991 [doi].

50. Luo L, Bokil NJ, Wall AA, Kapetanovic R, Lansdaal NM, Marceline F, et al. SCIMP is a transmembrane non-TIR TLR adaptor that promotes proinflammatory cytokine production from macrophages. Nat Commun. 2017;8: 14133. doi: 10.1038/ncomms14133 [doi].

51. Suzuki K, Okuno T, Yamamoto M, Pasterkamp RJ, Takegahara N, Takamatsu H, et al. Semaphorin 7A initiates T-cell-mediated inflammatory responses through alpha1beta1 integrin. Nature. 2007;446: 680-684. doi: nature05652 [pii].

52. Nguyen TT, Klasener K, Zurn C, Castillo PA, Brust-Mascher I, Imai DM, et al. The IgM receptor FcmuR limits tonic BCR signaling by regulating expression of the IgM BCR. Nat Immunol. 2017;18: 321-333. doi: 10.1038/ni.3677 [doi].

53. Blandino R, Baumgarth N. Secreted IgM: New tricks for an old molecule. J Leukoc Biol. 2019;106: 1021-1034. doi: 10.1002/JLB.3RI0519-161R [doi].

54. Savage HP, Klasener K, Smith FL, Luo Z, Reth M, Baumgarth N. TLR induces reorganization of the IgM-BCR complex regulating murine B-1 cell responses to infections. Elife. 2019;8: 10.7554/eLife.46997. doi: 10.7554/eLife.46997 [doi].

55. Castigli E, Wilson SA, Scott S, Dedeoglu F, Xu S, Lam KP, et al. TACI and BAFF-R mediate isotype switching in B cells. J Exp Med. 2005;201: 35-39. doi: jem.20032000 [pii].

56. Rowland SL, Leahy KF, Halverson R, Torres RM, Pelanda R. BAFF receptor signaling aids the differentiation of immature B cells into transitional B cells following tonic BCR signaling. $\mathrm{J}$ Immunol. 2010;185: 4570-4581. doi: 10.4049/jimmunol.1001708 [doi].

57. Nussenzweig RS, Vanderberg J, Most H, Orton C. Protective immunity produced by the injection of x-irradiated sporozoites of plasmodium berghei. Nature. 1967;216: 160-162. doi: 10.1038/216160a0 [doi].

58. Hoffman SL, Goh LM, Luke TC, Schneider I, Le TP, Doolan DL, et al. Protection of humans against malaria by immunization with radiation-attenuated Plasmodium falciparum sporozoites. J Infect Dis. 2002;185: 1155-1164. doi: JID010922 [pii].

59. RTS, S Clinical Trials Partnership. Efficacy and safety of RTS,S/AS01 malaria vaccine with or without a booster dose in infants and children in Africa: final results of a phase 3, individually randomised, controlled trial. Lancet. 2015;386: 31-45. doi: 10.1016/S0140-6736(15)60721-8 [doi].

60. Fox BA, Bzik DJ. Avirulent uracil auxotrophs based on disruption of orotidine-5'monophosphate decarboxylase elicit protective immunity to Toxoplasma gondii. Infect Immun. 2010;78: 3744-3752. doi: 10.1128/IAI.00287-10 [doi]. 